\title{
Participación en el suicidio y eutanasia. Esbozo del tratamiento penal en España*
}

\author{
Miguel Díaz y García Conlledo* \\ Soledad Barber Burusco***
}

A Juan Fernández Carrasquilla, con reconocimiento y afecto

\section{Resumen}

En el presente escrito se aborda la regulación en el caso español de conductas como la inducción o asistencia al suicidio de un lado, y la eutanasia, con sus diferentes modalidades, del otro. Se expresa cómo la regulación española en la materia es escaza y dista de ser clara; y las dificultades de aplicación de las normas mencionadas (además porque los conceptos de suicidio y eutanasia plantean complejidades en cuanto a su definición), y se hace una consideración al papel que juega en España el consentimiento cuando se pretende poner fin a la vida.

\footnotetext{
* $\quad$ El presente trabajo se enmarca en los proyectos de investigación DER2010-16558, Ministerio español de Ciencia e Innovación, ahora de Economía y Competitividad, en parte con fondos FEDER) y LE066A11-1 (Junta de Castilla y León), cuyo investigador principal es Miguel Díaz y García Conlledo y de cuyo equipo investigador forma parte Soledad Barber Burusco.

* $\quad$ Catedrático de Derecho Penal de la Universidad de León, España.

*** Profesora Titular de Derecho Penal de la Universidad Pública de Navarra, España.
} 


\section{Abstract}

This writing takes as matter the regulation in the Spanish law about behaviors, such as the inducement or assistance to suicide, form one side, and the euthanasia, from the other one. It is expressed how the Spanish regulation in this matter is poor and far from being clear; and the difficulties of application of these laws, making a consideration to the role played by the consent in Spain when it is pretended to end a life.

\section{Palabras Clave}

Inducción al suicidio, cooperación al suicidio, eutanasia, punibilidad, atenuación.

\section{Key words}

Inducement to suicide, cooperation to suicide, euthanasia, punishability, attenuation.

\section{Sumario}

1. Introducción; 2. Los conceptos de suicidio y eutanasia; 3. Las conductas típicas: algunas cuestiones comunes; 3.1. La inducción y la cooperación necesaria al suicidio; 3.1.1. Caracterización de la inducción; 3.1.2. Delimitación de la cooperación; 3.1.3. Relevancia de la conducta omisiva en la cooperación; 3.1.4. El resultado muerte del suicida y la tentativa; 3.1.5. Participación en la inducción y en la cooperación al suicidio; 3.2. El homicidio consentido y la cooperación ejecutiva al suicidio; 3.3. La eutanasia; 3.3.1. Algunas propuestas de regulación; 3.3.2. Consideraciones finales.

\section{Introducción}

El tratamiento jurídico-penal de la participación en el suicidio y de la eutanasia es de una notable complejidad, porque, sin duda, en la adopción de cualquier solución que se proponga para la determinación de los límites en esta clase de intervenciones relacionadas con el fin de la vida, entrarán o pretenderán entrar en juego perspectivas éticas, religiosas, antropológicas, médicas, ideológicas, junto a fuertes sentimientos, temores difusos, el tabú que rodea la muerte, etc.

Al cúmulo de perspectivas que pretenden influir en la adopción de soluciones en este ámbito debe sumarse un factor que añade confusión (tal vez debido a la multiplicidad de aportaciones, de origen y fines diversos), el de que las nociones, tanto de suicidio como de eutanasia, no son nada pacíficas, circunstancia que ayuda a complicar el entendimiento de muchas de las cuestiones, como veremos.

Actualmente, las soluciones legales que se dan a la cuestión en nuestro entorno pueden agruparse de la siguiente manera: a) algunas regulaciones dan una muy escasa 
relevancia al consentimiento, con lo que las conductas de participación en el suicidio ajeno se sancionan con notable severidad'; b) otras legislaciones, como la italiana (de manera muy genérica rebaja la pena establecida para el homicidio al que ocasiona la muerte de otro con su consentimiento, exceptuando supuestos de incapacidad y consentimiento viciado), la alemana (regula el homicidio a petición de forma atenuada, castigándolo con hasta cinco años de prisión y no castiga la inducción y el auxilio al suicidio), o la española (que veremos con más detalle), otorgan al consentimiento un papel lo suficientemente relevante como para atenuar de forma notable el castigo de determinados supuestos si lo comparamos con el previsto para el homicidio o el asesinato; y, finalmente, nos encontramos con c) ordenamientos legales que, bajo la exigencia de determinadas cautelas y para supuestos estrictamente determinados, se deciden por la no punición de algunas conductas².

En nuestro país, desde los años ochenta del siglo pasado, la evolución del pensamiento jurídico-penal en relación con el castigo (y el alcance del mismo) de la participación en el suicidio y la eutanasia ha estado estrechamente relacionada con el intento de interpretación de la legislación penal proveniente del Código Penal (CP) 1944/73³ y en vigor hasta 1996, a la luz de las disposiciones de nuestra Constitución

1 Por ejemplo, en el Reino Unido la asistencia al suicidio puede castigarse con una pena de hasta 14 años de prisión.

2 Así, la Ley holandesa (del año 2001) establece en el art. 293 de su CP que el que quitare la vida a otra persona, según el deseo expreso y serio de la misma, será castigado con la pena de prisión de hasta doce años o con pena de multa de la categoría quinta, pero añade un segundo inciso en el que dispone: "El supuesto al que se refiere el párrafo 1 no será punible en el caso de que haya sido cometido por un médico que haya cumplido los requisitos de cuidado recogidos en el artículo 2 de la Ley sobre comprobación de la terminación de la vida a petición propia y el auxilio a suicidio se haya comunicado al forense municipal conforme al artículo 7, párrafo segundo de la Ley reguladora de los funerales". A su vez, el art. 294 castiga la inducción al suicidio y el auxilio al suicidio con la pena de prisión de hasta tres años o multa de la categoría cuarta. Se aplicará por analogía el art. 293 párrafo segundo. La práctica, en Holanda, es objeto de serias críticas (V. Fernando Rey Martínez, Eutanasia y derechos fundamentales, Madrid, Centro de Estudios Constitucionales, 2008, pp. 46 ss.). También Bélgica, en el año 2002, aprobó una ley relativa a la eutanasia cuando es el médico el que controla todo el proceso. En 2009 Luxemburgo aprobó una ley que despenaliza la eutanasia y el suicidio médicamente asistido cuando lo solicita reiteradamente un sujeto mayor de edad o menor emancipado con pronóstico irreversible y graves sufrimientos sin esperanza de mejoría, debiéndose consultar el diagnóstico a otro médico. En EEUU, en el Estado de Oregón, se permiten estas conductas en caso de enfermedad terminal que previsiblemente lleve a la muerte en un plazo no superior a seis meses, debiendo prestar la asistencia un médico acompañado de un segundo médico consultor. El Estado de Washington se ha sumado a este último modelo en el año 2009. Peculiar es la solución suiza, donde la eutanasia está prohibida pero no la asistencia al suicidio practicada por cualquiera que actúe por motivos desinteresados, "no egoístas", según dispone el art. 115 del CP suizo, entendiéndose por tales los casos en los que el suicidio no reporta beneficios materiales ni de satisfacción de sentimientos de odio o venganza. No se prevé el derecho a exigir a las autoridades el auxilio al suicidio, pero existen organizaciones que realizan la tarea de acompañar a la persona que quiere suicidarse y proporcionarle la sustancia letal.

$3 \quad$ V. infra, pie de página n. 17. 
(CE) de 1978 relativas a los derechos fundamentales 4 ; aunque las diversas posiciones desarrolladas, en buena medida, pueden sustentarse respecto de los preceptos que sobre el tema prevé el vigente CP (en el que algunos supuestos como la mera complicidad han quedado sin castigo, y las penas previstas para la inducción, cooperación y cooperación ejecutiva -y homicidio consentido según se interprete- se han moderado y se prevén atenuaciones especiales para determinados supuestos eutanásicos).

Entre las cuestiones debatidas (respecto de las que existen posiciones diversas y con múltiples matices imposibles de detallar y analizar en este reducido espacio) se encuentra la de si puede encontrarse en el marco constitucional español un fundamento sólido relativo a un derecho a la disponibilidad de la propia vida.

Así, junto a posiciones que siguen sustentando que nuestro ordenamiento jurídico considera a la vida humana como un bien jurídico indisponible ${ }^{5}$ de la puesta en relación de los preceptos constitucionales relativos al reconocimiento del derecho a la vida, a la integridad física y moral y la prohibición de tratos inhumanos y degradantes (art. 15), a la dignidad humana y al libre desarrollo de la personalidad (art. 10), a la libertad ideológica y religiosa (art. 16) y al valor libertad (art. 1.1)

4 V. más extensamente, Bernardo Del Rosal Blasco, "El tratamiento jurídico-penal y doctrinal de la eutanasia en España", en Díez Ripollés, José Luis/Muñoz Sánchez, Juan (coords.), El tratamiento jurídico de la eutanasia. Una perspectiva comparada, Valencia, Tirant lo Blanch, 1996, pp. 43-73, pp. 54 s.

5 V. por muchos, Francisco Muñoz Conde, Derecho Penal. Parte Especial, 18. a', Valencia, Tirant lo Blanch, 2010, p. 61; Diego-Manuel Luzón Peña, "El consentimiento en Derecho penal: causa de atipicidad, de justificación o de exclusión sólo de la tipicidad" en Homenaje al Prof. Dr. Rodrigo Suárez Montes (en prensa); Santiago Mir Puig, Derecho Penal. Parte General, ga ed. a cargo de Víctor Gómez Martín, Barcelona, Reppertor, 2011, p. 320 n. 11, considera que nuestro Derecho concibe el derecho a la vida como "irrenunciable", y señala que esta concepción acogida por el CP está perdiendo terreno en la conciencia social, que parece evolucionar hacia una consideración de la vida como un bien personal del que ha de poder disponer libremente su titular.

6 Fernando Rey Martínez, Eutanasia, 2007, pp. 83 ss., sostiene que de nuestra Constitución se pueden deducir cuatro modelos diferentes de interpretación jurídica de la eutanasia activa directa: 1) el de la eutanasia prohibida, si se entiende la protección jurídica de la vida del art. 15 en sentido absoluto, pudiendo resultar inconstitucional la eventual despenalización de la misma. 2) El de la eutanasia como derecho fundamental, si el derecho fundamental a la vida sólo o en relación con otros derechos y principios constitucionales incluye en su contenido el derecho a disponer de la propia vida por su titular. No existe un deber de vivir. De ahí que tanto el suicidio como la eutanasia activa directa serían manifestaciones de un legítimo ejercicio de ese derecho fundamental y la incriminación penal de ambas conductas, sería inconstitucional, el art. 143.4 CP sería contrario (en todo o en parte) a la Constitución. 3) El modelo de la eutanasia como manifestación del principio de libertad constitucional, legislativamente limitable (variante técnicamente más rigurosa del modelo anterior), desde donde se sostiene que de la Constitución no se deduce un derecho fundamental a terminar con la propia vida de manera activa, pero la cláusula general de libertad del art. 1.1 CE ampara muchas conductas e impide a los poderes públicos imponer limitaciones no razonables, arbitrarias y desproporcionadas. Consecuencia de ello una prohibición del suicidio resultaría inconstitucional, pero una prohibición de la eutanasia como la del 143.4 CP no sería una restricción arbitraria de la libertad porque perseguiría evitar riesgos de abusos, pero 
conclusiones variadas en cuanto al alcance constitucional de la protección de la vida y su disponibilidad. Para algunos la disponibilidad de la propia vida, que puede derivarse de la Constitución, forma parte del propio bien jurídico vida ${ }^{7}$. Otro sector (con múltiples matices y variadas combinaciones) reconoce que puede derivarse de la Constitución la disponibilidad de la propia vida por parte de su titular ${ }^{8}$ y establece distintos efectos,

también se podrían despenalizar tales conductas bajo ciertas condiciones. 4) Y, por último, se podría considerar a la eutanasia como excepción legítima, bajo ciertas condiciones, de la protección estatal de vida, interpretación que propone como más plausible, que, al igual que el modelo anterior entendería conforme a la Constitución, bajo ciertas condiciones, una despenalización legislativa de la eutanasia y/o el suicidio asistido, pero se aparta del modelo anterior en que, una eventual despenalización es una excepción que debe interpretarse restrictivamente, sujetándose al principio de proporcionalidad como límite de límites de los derechos fundamentales, a diferencia del modelo de la libertad limitable, que puede tener una tendencia expansiva.

7 Juan Carlos Carbonell Mateu, “Libre desarrollo de la personalidad y delitos contra la vida. Dos cuestiones: suicidio y aborto" en Cuadernos de Política Criminal 45, 1991, pp. 661-672, p.664, integra los derechos constitucionales a la vida y a la libertad, interpretándolos a la luz del libre desarrollo de la personalidad, lo que le lleva a considerar que "solo la vida libremente deseada puede merecer el calificativo de bien jurídico protegido". Una posición cercana sustenta MirentXu CoRcoy BIDASOLo, "La regulación legal de la eutanasia en el CP español. Propuestas de reformas legislativas" en Mendoza Buergo, Blanca (ed.), Autonomía personal y decisiones médicas. Cuestiones éticas y jurídicas, Madrid, Civitas, 2010, pp. 299322 , p. 300, cuando afirma que los derechos fundamentales de la persona deben ser protegidos por los poderes públicos (respecto del Estado, la Constitución no le otorga un derecho sobre esos bienes jurídicos fundamentales, sino exclusivamente un deber de protegerlos), por lo que debería entenderse que ese deber de protección no existe cuando el titular no quiere ejercer ese derecho sino que, por el contrario, renuncia a él, esto determina que el propio titular del derecho es el único que tiene capacidad de decisión sobre cómo y en qué forma quiere ejercer ese derecho, porque "no se protege la vida en sí misma sino el interés que por la vida tiene su titular".

8 Bernardo Del Rosal Blasco,“La participación y el auxilio ejecutivo en el suicidio: un intento de reinterpretación constitucional del artículo 409 del Código Penal", en Anuario de Derecho Penal y Ciencias Penales, 1987, pp. 73- 97, pp. 85 ss; Bernardo Del Rosal Blasco,"El tratamiento jurídicopenal y doctrinal de la eutanasia en España", cit., pp. 63 s. considera que de la Constitución (arts. 10.1 y 15) se puede deducir, sin grandes inconvenientes el derecho a disponer de la propia vida, pero considera que se pueden legitimar determinadas prohibiciones de comportamientos de terceros; Ignacio Muñagoril Laguía, Eutanasia y Derecho penal, Madrid, Ministerio de Justicia e Interior, 1994, pp. 44 ss., entiende que una interpretación integradora de los preceptos constitucionales permite hablar de la disponibilidad de la propia vida por parte de su titular, mientras que las intervenciones de terceros sólo podrán alcanzar la licitud en situaciones inequívocas de conflicto; Enrloue Díaz Aranda, Dogmática del suicidio y homicidio consentido, Madrid, Centro de Estudios Judiciales, 1995, pp. 91 ss., afirma la existencia de un derecho fundamental a la autodeterminación de la vida por su titular, pero no faculta a la intervención de terceros; Jesús Toledano Toledano, Límites penales a la disponibilidad de la propia vida, Barcelona, Atelier, 1999, pp. 166 ss.; Carmen Tomás-Valente Lanuza, La cooperación al suicidio y la eutanasia en el nuevo CP (art.143), Valencia, Tirant lo Blanch, 2000, pp. 36 ss., derivan de un principio general de libertad la prohibición a los poderes públicos de imponer restricciones no razonables, por lo que resultaría contraria a la Constitución la prohibición del suicidio en sí mismo, pero no considera sencillo calificar de arbitrarios o no razonables los motivos de la prohibición de las conductas de colaboración en el suicidio ajeno; José Manuel Valle MuñIz, Quintero Olivares, Gonzalo (dir.), Comentarios a la Parte Especial del Derecho Penal, 8a , Pamplona, Aranzadi, 2009, pp. 70 ss., afirma que "si el texto constitucional no permite una interpretación del derecho a la vida incompatible con la dignidad humana, 
en cuanto a responsabilidad penal, a la contribución de terceras personas, limitando 0 negando, según los casos, tal responsabilidad. También se sostiene que la Constitución se refiere exclusivamente al ejercicio del derecho en su vertiente positiva, la de vivir y no la negativa, la de morir, y, en consecuencia, el derecho a prescindir de la propia vida no forma parte, en un primer análisis, del contenido del derecho fundamental. Pero la prohibición de tratos inhumanos o degradantes contenida en el mismo artículo 15 hace que las obligaciones de no hacer y hacer deban ser moduladas en el sentido de que en ningún caso su cumplimiento conlleve mantener la vida humana con procedimientos 0 en condiciones inhumanas o degradantes ${ }^{9}$.

Consideramos que la vida tiene una protección fragmentaria, no absoluta, como sucede con todo derecho fundamental. Y que, si bien de los preceptos constitucionales pueden efectuarse múltiples lecturas (con mayor o menor peso argumental), nos parece más acertada la afirmación de que el derecho a la vida en nuestra Constitución se encuentra configurado como un derecho de garantía en su vertiente positiva, que nada se desprende "directamente" de ella respecto de su posible vertiente negativa (derecho constitucional a morir, derecho a exigir que terceros auxilien o ejecuten la muerte de otro en determinadas circunstancias). Sí participamos de la idea de que la vida es un bien jurídico disponible para su titular, en el sentido de que no existe el deber de vivir contra la propia voluntad y nada faculta a que el Estado pueda imponer seguir viviendo contra una decisión individual la la inversa, podría afirmarse la inconstitucionalidad, por ejemplo, del castigo de la tentativa de suicidio). Como auxilio a la afirmación de la vida como bien jurídico disponible para su titular en nuestro ordenamiento, sirve la constatación de que el suicidio realizado por el interesado es un hecho lícito, esto es, no antijurídico, en la medida en que en nuestro derecho positivo no se encuentra ninguna consecuencia jurídica negativa para quien se suicide o intente suicidarse por sus propios medios.

y si ésta supone el rechazo de cualquier intento de instrumentalización, en aras de salvaguardar el libre desarrollo de la personalidad, es indudable que el sujeto puede disponer libremente de su vida, y que el acto del suicidio es expresión del ejercicio de un derecho constitucionalmente amparado."

9 José Luis Díez Ripollés, “Eutanasia y Derecho” en Díez Ripollés, José Luis/ Muñoz Sánchez, Juan (coords.) El tratamiento jurídico de la eutanasia. Una perspectiva comparada, Valencia, Tirant lo Blanch, 1996, pp. 509-546, pp. 519 ss.; José Luis Díez Ripoltés, Díez Ripollés, José Luis/Gracia Martín, Luis (coords.), Comentarios al Código Penal, I, Valencia, Tirant lo Blanch, 1997, pp. 164-266, pp. 177 ss. Una posición cercana mantiene Carlos Romeo Casabona, Los delitos contra la vida y la integridad personal y los relativos a la manipulación genética, Granada, Comares, 2004, p. 94, para quien no existe un derecho a la disponibilidad de la propia vida, o un derecho a la muerte, sustentado en el art. 15 CE o en otros preceptos de la misma, sino una libertad o facultad, no exigible constitucionalmente (es decir, ni a los poderes públicos ni a terceros) de disponer de ella por uno mismo. Sin embargo, tampoco existe el deber de vivir contra la propia voluntad, y, por tanto, al ser un derecho de garantía, no faculta a los particulares ni al Estado para imponer seguir viviendo contra la decisión individual. Sí considera compatible con la CE que se involucre a un tercero en la decisión de quitarse uno la propia vida, siempre que el titular del derecho conserve un control sobre el proceso, pero no se puede inferir de ello que se sustente en un derecho constitucional. 
Pero la afirmación de la licitud del suicidio respecto de la propia vida no implica que, en el plano de la legalidad ordinaria, el legislador no pueda intervenir frente a personas que participan en él con el objeto de prevenir abusos que podrían cometerse en el contexto del suicidio, circunstancia que permite justificar la tipificación de la inducción y de la cooperación necesaria al suicidio, aunque también puedan no incriminarse estas conductas. Ambas decisiones, de carácter político-criminal, resultan compatibles con las disposiciones constitucionales, como también resulta compatible con nuestra Constitución una regulación de la eutanasia para supuestos precisos y con determinadas garantías de procedimiento.

\section{Los conceptos de suicidio y eutanasia}

Ya anticipamos que en nuestra doctrina penal no existe un concepto pacífico de suicidio. La primera discrepancia se relaciona con el hecho de que el suicidio sea un acto eminentemente personal que realiza el propio suicida en el sentido de "quitarse uno mismo la vida", lo que implica que es necesario que el suicida controle en todo momento el proceso de producción de la muerte (que mantenga el dominio del hecho), 0, por el contrario, baste para calificarlo como tal la manifestación de la voluntad de morir ${ }^{10}$. La segunda gira en torno a si el comportamiento suicida abarca conductas sólo activas por parte del sujeto activo -el suicida- o también omisivas ${ }^{11}$. La tercera se encuentra relacionada con la capacidad requerida al sujeto activo (al suicida) para caracterizar su acto como suicidio ${ }^{12}$. Y, finalmente, existen también diferencias a la hora

10 Exigen el dominio del hecho o similar, entre otros, Jesús María Silva Sánchez, "Causación de la propia muerte y responsabilidad penal de terceros" en Anuario de Derecho Penal y Ciencias Penales, 1987, pp. 451-477, pp. 456-457; Miguel Díaz y García Conlledo, "Homicidio consentido, participación en el suicidio y eutanasia" en Luzón Peña, Diego-Manuel (dir.), Enciclopedia Penal Básica, Granada, Comares, 2002, pp. 764-782, p. 765; Carmen Tomás-Vallente Lanuza, Disponibilidad de la propia vida en el la Derecho Penal, Madrid, Boletín Oficial del Estado, 1999, p. 397, n. 6; Carmen Tomás-Valiente Lanuza, La cooperación al suicidio y la eutanasia en el nuevo CP (art.143), 2000, p. 54; Carlos Romeo Casabona, Los delitos contra la vida y la integridad personal y los relativos a la manipulación genética, cit., pp. 98 s.; GISELE MENDES DE Carvalho, Suicidio, eutanasia y Derecho Penal, Granada, Comares, 2009, p.223 n.1. Considera que basta la voluntad de morir: Ángel Torío López, "La noción jurídica de suicidio" en Estudios de Derecho Público y Privado. Homenaje a D. Ignacio Serrano y Serrano, I, Valladolid, 1965, pp. 653-668, p. 663, quien define al suicidio como "muerte querida por una persona imputable.

11 En el sentido de equiparar ambas se pronuncian, entre otros, Jesús María Silva Sánchez, ADPCP, 1987, pp. 454 s.; José Luis Díez Ripollés, José Luis/Gracia Martín, Luis (coords.), Comentarios al Código Penal, cit., p. 191; Carlos Romeo Casabona, Los delitos contra la vida y la integridad personal y los relativos a la manipulación genética, cit., p. 99. De opinión contraria, Francisco Bueno Arús, "Límites del consentimiento en la disposición del propio cuerpo desde la perspectiva del Derecho penal" en Poder Judicial n. 15., 1985, pp. $11 \mathrm{~s}$.

12 Exigen que no sea inimputable Ángel Torío López, Homenaje a D. Ignacio Serrano y Serrano, cit., p. 663; le sigue: Carmen Tomás-Lanzuza, La cooperación al suicidio y la eutanasia en el nuevo CP (art.143), cit., p. 42; F. Javier Álvarez García, Álvarez García, F. Javier, (Dir) Derecho Penal Español, Parte Especial, I, 
de exigir una voluntad directa 0 eventual de perseguir la muerte ${ }^{13}$. Las consecuencias de la adopción de una u otra posición dan como resultado un concepto más amplio 0 restringido de lo que se entiende por suicidio e impacta en la caracterización jurídica que se realice de la intervención de terceros en estas conductas.

En cuanto a la eutanasia, existen múltiples conceptos y clasificaciones imposibles de detallar aquí ${ }^{14}$, pero, a fin de evitar su confusión con otras figuras, reservaremos el término eutanasia (buena muerte) para los casos en que se da muerte a o no se evita la muerte de un sujeto que sufre una enfermedad 0 un deterioro graves e incurables (o permanentes) y, según una parte de las opiniones al respecto, conducentes a la muerte 0 , al menos, generadores de sufrimientos difíciles de soportar 0 un calidad de vida ínfima, existiendo, según algunos, consentimiento, y, según otros, petición libre y responsable de quien va a morir. Si no existiera consentimiento (y, naturalmente, en los casos en que el sujeto pasivo no pueda prestarlo, se plantea el difícil problema de quién y en qué situaciones puede hacerlo), nos hallaríamos ante un homicidio (en sentido amplio), que podría estar atenuado en ocasiones cuando el sujeto activo es motivado por móviles positivos (piedad, evitación de sufrimientos, etc.). No serán

Valencia, Tirant lo Blanch, 2010, p. 97, parte de las estructuras de la imputabilidad y sobre ello exige la capacidad para comprender el sentido y trascendencia de la resolución de la voluntad en relación con el bien jurídico protegido; Miguel Olmedo Cardente, "Eutanasia, suicidio y Derecho penal en España. Responsabilidad penal por la intervención en el suicidio ajeno y en el homicidio consentido" en Eutanasia y suicidio. Cuestiones dogmáticas y de política criminal, Granada, Comares, 2001, pp. 105-154, p. 115, al requisito de la imputabilidad, que en su opinión debe ser plena, añade que el suicida no puede ser menor de 18 años. Otro sector exige la capacidad natural de entendimiento o de juicio, es decir la capacidad de comprender la trascendencia de su comportamiento: José LuIs DíEz Ripollés, José Luis/ Gracia Martín, Luis (coords.), Comentarios al Código Penal, cit., pp. 187 s.; Jorge Barrelro, Agustín, Rodríguez Mourullo, Gonzalo (dir.) Comentarios al Código Penal, Madrid, Civitas, 1997, p. 411; Carlos Romeo Casabona, Los delitos contra la vida y la integridad personal y los relativos a la manipulación genética, cit., p. 103; Mirentxu Corcoy Bidasolo/José Ignacio Gallego Soler, "Política criminal en el ámbito de la disponibilidad de la vida humana" en Mir Puig, Santiago/Corcoy Bidasolo, Mirentxu (dirs.) Política criminal y reforma penal, Montevideo-Buenos Aires, B de F, 2007, pp. 220- 272, p. 227; GISELE MENDES DE Carvalho, Suicidio, eutanasia y Derecho Penal, cit., p. 233; José Manuel Valle MuñIz, Quintero Olivares, Gonzalo (dir.), Comentarios a la Parte Especial del Derecho Penal, cit., p. 76. Finalmente, también, y sin diferenciarse excesivamente de la posición anterior, exigen la capacidad para consentir en la lesión de bienes jurídicos, Miguel Bajo Fernández, PE, I, 1991, p. 91; Juan José González Rus, PE, 2005 p. 107.

13 Exige dolo directo, entre otros, Agustín Jorge Barrelro, Rodríguez Mourullo, Gonzalo (dir.) Comentarios al Código Penal, cit., p. 412; admiten también la posibilidad del dolo eventual, Jesús María Silva Sánchez, ADPCP, cit., p. 656 s.; Miguel Díaz y García Conlledo, Luzón Peña, Diego-Manuel (dir.), Enciclopedia Penal Básica, cit., p. 765; y, finalmente, incluye el dolo directo y de las consecuencias necesarias pero excluye el eventual Carmen Juanatey Dorado, Javier Boix Reig (dir.), Derecho Penal. Parte Especial, I, lustel, 2010, p. 68.

14 V. ampliamente respecto a las distintas clasificaciones, entre otros, Carlos Romeo Casabona, Derecho y bioética ante los límites de la vida humana, Madrid, 1994, pp. 421 ss.; Miguel Angel Núñez Paz, Homicidio consentido, eutanasia y derecho a morir con dignidad, Madrid, Tecnos, 1999, pp. 31 ss., Miguel Ángel Núñez Paz, La buena muerte. El derecho a morir con dignidad, Madrid, Tecnos, 2006, pp. 89 ss.; Gisele Mendes de Carvalho, Suicidio, eutanasia y Derecho Penal, cit., pp. 267 ss. 
generadores de responsabilidad penal los supuestos de ortotanasia (muerte recta), si por tales se entiende (aunque el término es usado en diferentes sentidos) aquellos en que se ayuda a "bien morir", es decir, se dan al enfermo medios paliativos de sus sufrimientos que no acortan (o no se puede probar que acorten) sensiblemente su vida (es más, los médicos tienen el deber, como mínimo deontológico, pero seguramente jurídico, de procurar el alivio del enfermo, no pudiendo descartarse que, al menos en algunos casos, la negativa pueda llegar a constituir un delito de omisión de socorro).

Se distingue básicamente entre dos clases de eutanasia. Por un lado, la eutanasia pasiva es aquella en que el sujeto no produce (ni siquiera acelerándola) en modo alguno la muerte del enfermo, sino que deja que este muera, no impide esa muerte, no prolonga, pudiendo hacerlo (manteniéndola mediante medios técnicos, farmacológicos, médicos en sentido amplio, etc.), su vida. Por eutanasia activa se entiende el supuesto en que un sujeto, de una forma u otra, realiza conductas de matar (en sentido naturalístico y, al menos en la eutanasia activa directa, también en sentido jurídico, sobre el enfermo), no tratándose simplemente de dejarle morir. Se puede distinguir entre eutanasia activa directa, en la que se utilizan medios directamente encaminados a provocar la muerte del enfermo, y eutanasia activa indirecta, en la que, a consecuencia de un tratamiento paliativo del sufrimiento se produce un acortamiento relevante y constatable del tiempo de vida 0 , si se prefiere, una aceleración del proceso de muerte ${ }^{15}$.

En la distinción entre eutanasia activa y pasiva y las consecuencias que conlleva, la terminología es fuente de frecuentes confusiones, incluso entre los especialistas y mucho más entre los profanos. Por ello es importante aclarar que no debe identificase eutanasia pasiva con no hacer, ni con mera pasividad, con lo que suele entenderse como modalidad omisiva de conducta, ni la activa con comisión activa, hacer, actuar positivamente. Esta identificación lleva a criticar la distinción entre eutanasia pasiva y activa, señalando que no suponen una diferencia sustancial en cuanto a gravedad. Sin embargo, creemos que la diferencia real existe y es material y valorativa (no meramente naturalística), y viene a coincidir con la distinción general en el derecho penal entre omisión pura o propia (incluyendo los supuestos de omisión por hacer),

15 En relación a esta caracterización y clasificación de la eutanasia, que es la aceptada launque con matices) por la mayoría de la doctrina penal, José Luis DíEz Ripolúśs, El tratamiento jurídico de la eutanasia, cit., pp. 514 ss., la considera poco útil para profundizar en lo que es la eutanasia. Sirve, a su criterio, para determinar lo que sería el "delito eutanásico", es decir, que el análisis detallado está condicionado por las características que resultan relevantes para decidir sobre la responsabilidad jurídico-penal de la persona que incide sobre la situación conflictiva intentando, correcta o incorrectamente, resolverla. Entiende que corresponde, como tarea previa, diferenciar las diversas situaciones eutanásicas y ponerlas en relación con las diferentes secuencias temporales conducentes a la muerte, a fin de recuperar la claridad y la neutralidad conceptuales en la definición de la eutanasia antes de realizar cualquier valoración jurídica. Propone una clasificación de los supuestos eutanásicos en tres grandes grupos: eutanasia terminal, paliativa y cualitativa que estructura combinando determinadas situaciones clínicas desfavorables con la secuencia temporal por medio de la cual se produce la muerte. 
que se correspondería con la eutanasia pasiva, y la comisión (incluida la comisión por omisión), que correspondería con la activa. Si bien bastantes supuestos de eutanasia pasiva se llevarán a cabo mediante abstenciones de actuar, habrá casos bastante frecuentes en que se realizarán conductas activas (por ejemplo, desconexión de un aparato previamente conectado para el tratamiento ${ }^{16}$ ) que sin embargo equivalgan a una mera no actuación (por ejemplo, en los casos en que el aparato que se desconecta no haya logrado mejorar en absoluto la situación del paciente ni lo logrará, situación en que la desconexión del aparato equivale a la no conexión inicial); en ellos estaremos también ante omisiones puras (lo que se conoce como omisión por hacer). Y, a la inversa, aunque la eutanasia activa se realice a menudo mediante conductas activas (por ejemplo, la administración de una inyección letal), es posible que ciertas conductas de abstención de actuar equivalgan material y valorativamente a ese hacer positivo. Simplificadamente, entre eutanasia pasiva y activa habrá la misma diferencia que entre dejar morir y matar.

\section{Las conductas típicas: algunas cuestiones comunes}

El CP español castiga expresamente algunos actos de participación en el suicidio, no excluye de la tipicidad el homicidio consentido, y matiza la responsabilidad penal en ciertos supuestos de eutanasia.

El art. 143 CP, último del Título I del Libro II, dedicado al "Homicidio y sus formas" -nos hallamos ante delitos contra la vida-, reza así: "1. El que induzca al suicidio de otro será castigado con la pena de prisión de cuatro a ocho años./ 2. Se impondrá la pena de prisión de dos a cinco años al que coopere con actos necesarios al suicidio de una persona./ 3. Será castigado con la pena de prisión de seis a diez años si la cooperación llegara hasta el punto de ejecutar la muerte./ 4. El que causare o cooperare activamente con actos necesarios y directos a la muerte de otro, por la petición expresa, seria e inequívoca de éste, en el caso de que la víctima sufriera una enfermedad grave que conduciría necesariamente a su muerte, o que produjera graves padecimientos permanentes y difíciles de soportar, será castigado con la pena inferior en uno o dos grados a las señaladas en los números 2 y 3 de este artículo".

Las figuras de los números 1 y 2 son sin duda formas de participación en un hecho atípico, el suicidio; en concreto se trata respectivamente de inducción y de cooperación necesaria, que han sido elevadas a la categoría de tipo autónomo por la ley. La naturaleza de la figura del número 3 resulta más discutible, pues puede sostenerse que se trata de un homicidio consentido, de una participación ejecutiva en el suicidio (en cuyo caso el homicidio consentido estaría castigado en el tipo general de homicidio

16 Extensamente, sobre el carácter activo u omisivo de las conductas de desconexión, CARMEN TomásValiente LanUzA, La cooperación al suicidio y la eutanasia en el nuevo CP (art.143), cit., pp. 113-124. 
del art. 168 CP), o de ambas cosas. Finalmente, el número 4 tipifica (privilegiándolas, al menos teóricamente) algunas conductas relacionadas con la eutanasia activa ${ }^{17}$. Como sin duda las conductas de los números 1 y 2 del art. 143 CP tienen como referencia el suicidio, la del número 3 , en alguna de las interpretaciones posibles, también, y parcialmente el número 4 podría también englobar casos de cooperación necesaria "eutanásica" al suicidio, conviene señalar brevemente qué se entiende por "suicidio", a los efectos de iniciar el análisis de las conductas típicas. Aunque la cuestión es debatida desde diversos prismas, creemos que, a los efectos que aquí interesan y sin entrar en matices, hay que entender por suicidio ${ }^{18}$ la muerte que se da a sí misma una persona determinando positivamente la muerte -si se prefiere, con dominio del hecho-, o sea con una conducta de autoría, y sin ser utilizado a su vez por otra persona como instrumento, pues, en este último caso, aunque en ocasiones quizá cupiera hablar de suicidio, la persona que utiliza a la víctima como instrumento será autor mediato de un homicidio y no partícipe en un suicidio (en este sentido se puede decir que el hecho del suicida ha de ser libre y responsable ${ }^{19}$ para que las conductas

17 Las novedades que el art. 143 CP presenta respecto a su predecesor en el CP 1944/73, el art. 409 de ese Código, son relevantes. Destacan las siguientes: se excluyen claramente de la tipicidad las conductas de complicidad (cooperación no necesaria) en el suicidio, que antes encajaban literalmente en el tipo; es totalmente novedosa la referencia a las conductas relacionadas con la eutanasia recogidas en el número 4 del artículo $143 \mathrm{CP}$; respecto del resto de las conductas se observa una suavización general de las penas, especialmente en comparación con la del homicidio, pues en el CP 1944/73 la figura (de discutida naturaleza) de lo que hoy es el número 3 del art. $143 \mathrm{CP}$ se castigaba con idéntica pena a la del homicidio (reclusión menor), mientras que hoy se castiga con una pena notablemente inferior, que no se solapa siquiera con la del homicidio; las penas de la inducción y la cooperación 0 auxilio al suicidio eran en la anterior legislación iguales entre sí (prisión mayor) y siempre inferiores a la del auxilio ejecutivo al suicidio, mientras que hoy son diferentes, superior para la inducción (prisión de cuatro a ocho años) que para la cooperación necesaria al suicidio (prisión de dos a cinco años), aunque solapadas entre sí (de manera que puede haber supuestos de concretos de cooperación necesaria que se castiguen con pena superior que otros de inducción), y, a su vez, en ambos casos inferiores a las de la figura del art. $143.3 \mathrm{CP}$, si bien el caso de la inducción se solapa con ella (de modo que también puede haber supuestos concretos de inducción al suicidio que resulten más penados que otros del art. 143.3 CP). Para un análisis más detallado de la regulación anterior, V. Miguel Díaz y Carcía Conlledo, “Homicidio consentido, participación en el suicidio y eutanasia" cit., pp. 3331-3335.

18 De igual forma en Miguel Díaz y García Conlledo, Luzón Peña, Diego-Manuel (dir.), Enciclopedia Penal Básica, cit., pp. 764-782, p. 765; Jesús María Silva Sánchez, ADPCP, cit., pp. 451-477, pp. 456 s.; Carmen Tomás-Valente Lanuza, Disponibilidad de la propia vida en el Derecho Penal, cit., p. 397, n. 6; Carmen Tomás-Valiente Lanuza, La cooperación al suicidio y la eutanasia en el nuevo CP (art.143), cit., pp. 98 s.; Gisele Mendes de Carvalho, Gisele, Suicidio, eutanasia y Derecho Penal, cit., p. 223, n. 1.

19 Los criterios que la doctrina propone a fin de distinguir el comportamiento libre y responsable del que no lo es difieren: Ánget ToRío López, Homenaje a D. Ignacio Serrano y Serrano, cit., p. 663, considera que no puede considerarse suicida la conducta de las personas inimputables, le sigue: CARMEN Tomás-Valiente Lanuza, Carmen, La cooperación al suicidio y la eutanasia en el nuevo CP (art.143), cit., p. 42. F. Javier Álvarez García, Álvarez García, F. Javier, (Dir) Derecho Penal Español, Parte Especial, cit., p. 97, parte de las estructuras de la imputabilidad y sobre ello exige la capacidad para comprender el sentido y trascendencia de la resolución de la voluntad en relación con el bien jurídico protegido; Miguel OLmedo 
de terceros intervinientes sean de participación en él). A ello hay que añadir la nota de que la propia muerte se realice al menos con dolo eventual ${ }^{20}$. Como consecuencia de esta caracterización la participación en el suicidio se diferencia de otras figuras como el homicidio consentido o incluso a petición de la víctima, en que en estas quien determina positivamente la muerte -quien posee el dominio del hecho, quien es autor de la muerte, quien mata- es el tercero y no el que muere.

Todas las figuras del artículo 143 CP requieren dolo y no es típica la comisión por imprudencia. La razón fundamental para afirmarlo es que no se tipifica expresamente la modalidad imprudente (art. $12 \mathrm{CP}$ ). E incluso si pudiera caber la duda de si algunas de las figuras del art. 143 CP (en concreto las que no sean de participación en el suicidio, sino de autoría de la muerte) podrían encajar en el tenor literal del art. 142 CP, cuyo número 1 dispone que "el que por imprudencia grave causare la muerte de otro, será castigado con pena de prisión de uno a cuatro años" (o en la correspondiente falta de homicidio por imprudencia leve del art. 621.2 CP), la propia ubicación de este artículo en el Título I del Libro II CP, detrás de la regulación del homicidio doloso y el asesinato y antes del artículo 143 CP indica a las claras que la comisión imprudente (si es posible) de las conductas descritas en este último artículo cae fuera del alcance del artículo 142 (y consecuentemente, también del art. 621.2) CP y resulta atípica. Naturalmente, cabe aportar otros argumentos, como la propia naturaleza y estructura de las figuras del art. 143 CP o el hecho de que, en los supuestos (si fueran posibles) de comisión de éstas por imprudencia grave, de aplicar el art. 142 CP se produciría una desproporción de la penalidad en comparación con la del delito doloso y, sobre todo, en la comparación entre las penas de los delitos del art. 143 CP y el homicidio cuando son dolosos y cuando fueran imprudentes.

Tampoco son punibles los actos preparatorios de las figuras del art. 143. Ello resulta absolutamente claro, por no tipificarse expresamente la conspiración,

Cardente, Eutanasia y suicidio, 2001, p. 115, al requisito de la imputabilidad, que en su opinión debe ser plena, añade que el suicida no puede ser menor de 18 años. Otro sector exige la capacidad natural de entendimiento o de juicio, es decir la capacidad de comprender la trascendencia de su comportamiento: José Luis Díez Ripollés, Díez Ripollés José Luis/Gracia Martín, Luis (coords.), Comentarios al Código Penal, cit., pp. 187 s.; Agustín Jorge Barreiro, Gonzalo Rodríguez Mourullo, (dir.) Comentarios al Código Penal, cit., p. 411; Carlos Romeo CASABona, Los delitos contra la vida y la integridad personal y los relativos a la manipulación genética, cit., p. 103; Mirenxtu Corcoy Bidasolo/ José Ignacio Gallego Soler, Política criminal y reforma penal, 2007, p. 227; Gisele Mendes de Carvalho, Suicidio, eutanasia y Derecho Penal, cit., p. 233; José Manuel Valle Muñiz, Quintero Olivares, Gonzalo (dir.), Comentarios a la Parte Especial del Derecho Penal, cit., p. 76. Finalmente, también y sin diferenciarse excesivamente de la posición anterior, exigen la capacidad para consentir en la lesión de bienes jurídicos, Miguel Bajo Fernández, PE, I, 1991, p. 91; Juan José González Rus, PE, cit., p. 107.

20 Tampoco es pacífica la doctrina en la exigencia de este requisito. Exige dolo directo: Agustín Jorge BarReiro, Rodríguez Mourullo, Gonzalo (dir.) Comentarios al Código Penal, cit., p. 412; admiten también la posibilidad del dolo eventual, Jesús María Silva Sánchez, ADPCP, cit., y, finalmente, incluye el dolo directo y de las consecuencias necesarias pero excluye el eventual Carmen Juanatey Dorado, PE, 2010, p. 68. 
proposición y provocación (ni la apología como forma de esta última ${ }^{21}$ para estos delitos. Sin embargo, sí consideramos punible la tentativa de los delitos del art. 143 CP y volveremos a referirnos a esta cuestión en el apartado siguiente.

\subsection{La inducción y la cooperación necesaria al suicidio}

En los números 1 y 2 respectivamente del art. 143 CP se castiga la inducción y la cooperación necesaria al suicidio. Por tanto, de las tres formas de participación en sentido estricto que expresamente conoce el CP español en relación con la intervención en un delito (aquí se participa en un hecho atípico, el suicidio) sólo queda excluida la complicidad o cooperación no necesaria ${ }^{22}$. Esta selección se debe a que la ley sólo ha considerado merecedoras y necesitadas de pena las intervenciones en un suicidio que resulten de especial importancia para la producción de éste: la inducción crea en el sujeto la decisión de suicidarse, y la cooperación necesaria contribuye al suicidio "con un acto sin el cual no se habría efectuado", si seguimos la definición de la letra b) de la segunda parte del art. 28 CP. En definitiva, ambas conductas determinan, no del modo positivo propio de la autoría ${ }^{23}$, pero sí de un modo negativo, el hecho.

La inducción y la cooperación necesaria de las letras a) y b) de la segunda parte del art. 28 CP dan lugar a un marco penal idéntico entre sí y, a su vez, idéntico al de la autoría, en concreto, para el delito consumado, la que establezca el correspondiente tipo de la parte especial. Sin embargo, en los números 1 y 2 del art. 143, el CP no aplica la misma lógica. Naturalmente la pena no puede ser la del autor del hecho al que se induce o coopera, pues el suicidio es atípico (y por ello se tipifican expresamente la inducción y la cooperación necesaria al mismo, que serían atípicas según las reglas generales de la participación). Pero lo llamativo es que el CP no establece el mismo marco penal para la inducción y para la cooperación necesaria al suicidio, sino uno superior para la primera de estas figuras (art. 143.1: prisión de cuatro a ocho años, para la inducción; art. 143.2: prisión de dos a cinco años para la cooperación necesaria). Ello indica que se ha seguido la idea (minoritariamente postulada también en ocasiones en materia de participación) de que, con carácter general, la inducción supone un hecho más grave que las otras formas de participación (incluida la cooperación necesaria),

21 Definidas en los arts. 17 y $18 \mathrm{CP}$

22 Prevista en el art. 29 CP: "Son cómplices los que, no hallándose comprendidos en el artículo anterior, cooperan a la ejecución del hecho con actos anteriores o simultáneos." Critica radicalmente esta decisión del legislador Carmen Tomás-Valente Lanuza, La cooperación al suicidio y la eutanasia en el nuevo $C P$ (art.143), cit., pp.50 s., por considerar inadecuado que la frontera de la punibilidad venga marcada por la mayor o menor entidad de la colaboración aportada sin precisar previamente el legislador el concepto jurídico de suicidio.

23 Conforme al concepto de autoría que se sustenta, v., resumidamente y entre otros muchos trabajos, Miguel Díaz y García Conlledo, "Autoría", en EPB, 2002, pp. 139-153. 
precisamente por hacer nacer en el sujeto ex novo la decisión, en este caso, de suicidarse, poniendo en marcha una cadena causal cuyo control se deja en manos de otro (el suicida), mientras que en la cooperación, aunque sea necesaria, el acontecer que desemboca en el suicidio de la persona (y por tanto, el peligro para la vida) ya está en cierta manera en marcha ${ }^{24}$. No obstante, la ley ha tenido en cuenta que, aun desde esa perspectiva, puede haber cooperaciones tan importantes que influyan en el suicidio tanto o más que la propia inducción (0, más precisamente, que algunos supuestos de ella), aunque ello no suceda con carácter general; por ello, los marcos penales de las dos figuras se solapan (entre los cuatro y los cinco años de prisión) atemperando la idea de la mayor gravedad de la inducción y posibilitando cierta flexibilidad.

\subsubsection{Caracterización de la inducción}

La inducción al suicidio (art. 143. 1 CP) ha de reunir los caracteres que normalmente se predican de la inducción al delito (salvo que, naturalmente, el suicidio no es delito). Así, ha de crear ex novo en la persona la decisión de suicidarse. La inducción debe producirse, en nuestra opinión, incitando a las claras, abiertamente (sentido que para nosotros posee la exigencia del carácter directo de la inducción como forma de participación en el $\mathrm{CP}^{25}$ ), requisito que no viene expresamente recogido en el art. 143.1 CP. Se plantea, en relación con esta característica, qué sucede cuando la inducción no es directa; así, por ejemplo, cuando a un sujeto con fuertes tendencias depresivas se le dice que padece una enfermedad incurable de la que fallecerá al cabo de un año con intensos dolores, con la intención de que se suicide, pero sin incitarle directamente a ello (y no reuniendo el supuesto los caracteres de la autoría mediata de homicidio, que se darán en algunos casos). Una primera interpretación posible sería, con un argumento sistemático a contrario, sostener que, como en el art. 28 CP se menciona expresamente el carácter directo de la inducción y en el art. 143.1 CP no, en este cabe tanto la inducción directa como la indirecta. Pero sistemática y teleológicamente resulta muy discutible establecer menores requisitos para la inducción a un hecho atípico (el suicidio) que para la inducción a un delito, por lo que creemos que esta interpretación debe ser descartada. Tampoco parece posible seguir la vía, aceptable, pero no pacífica en materia de inducción al delito,

24 Se pronuncian a favor de considerar más grave la inducción que la cooperación necesaria CarmeN Juanatey Dorado, PE, cit., pp. 70 s.; Jesús Toledano Toledano, Límites penales a la disponibilidad de la propia vida, cit., pp. 179 y 181. En sentido contrario, critica el apartamiento en el caso de la cooperación al suicidio de las reglas generales de la participación Miguel Olmedo Cardente, Eutanasia y suicidio, cit., pp. 129 s., argumentando que ha sido la imagen que históricamente se posee del inductor como auténtico autor moral o espiritual del hecho ly no su moderna concepción como forma de participación accesoria) la que ha influido en la previsión de una mayor penalidad para la instigación al suicidio. 
de castigarla como un acto preparatorio de proposición, puesto que no se castigan, como sabemos, los actos preparatorios de los delitos del art. $143 \mathrm{CP}$, no constituyendo además este supuesto una proposición a un hecho del art. 143. CP, sino a un hecho atípico, el suicidio: los casos de proposición punible se refieren siempre a la proposición a un delito y, además, su castigo ha de estar expresamente previsto por la ley (art. 17.3 CP). La última posibilidad para castigar esta forma de inducción indirecta al delito será la de incluirla en el art. 143.2 CP (con un marco penal menos severo, aunque solapado con el de la inducción del número 1 del mismo artículo) como cooperación necesaria al suicidio, pero sólo en los casos en que concurra el requisito de ser necesaria, cosa que no tiene por qué suceder siempre (cuando así no sea, la inducción indirecta al suicidio será impune por atípica).

De este modo se consigue seguramente una solución flexible, que permite el castigo de los casos más graves de inducción indirecta, si bien teniendo en cuenta las diferencias de intensidad de la influencia en la resolución de suicidarse en comparación con la inducción directa (que normalmente estará más penada, salvo casos excepcionales que podrán reflejarse gracias al solapamiento de marcos penales anteriormente mencionado) y también comparando el grado de influencia real entre unas formas de inducción indirecta y otras (las necesarias, punibles, y las no necesarias, impunes $)^{26}$.

La inducción al suicidio ya deja de ser tal ("por arriba"), y no se castigará por el art. $143.1 \mathrm{CP}$, sino más gravemente, en aquellos casos en que, con una conducta inductora, el sujeto que induce pase a ejercitar la determinación positiva de la muerte del que se quita la vida (si se prefiere, domine positivamente el hecho), por producirse una instrumentalización de este último. Estos serán casos de autoría mediata ${ }^{27}$ de homicidio 0 , en su caso, de asesinato.

\subsubsection{Delimitación de la cooperación}

Para que resulte punible, la cooperación al suicidio ha de ser necesaria. Aunque la terminología del art. 143.2 ("coopere con actos necesarios") y la segunda parte del art. 28 CP ("cooperan a su ejecución -scil. del hecho- con un acto sin el cual no se habría efectuado") no son coincidentes, parece claro el paralelismo de las dos figuras, que resultan idénticas, salvo en que (al margen de las peculiaridades penológicas señaladas) en la primera se coopera a un hecho atípico, el suicidio, y, en la segunda, a un hecho típicamente antijurídico (delito o falta). Por ello, parece que, con las matizaciones que procedan por esta peculiaridad, para la caracterización de la

26 En este sentido, Miguel Díaz y García Conlledo, EPB, cit., p. 768.

27 De acuerdo a lo dispuesto en el art. $28 \mathrm{CP}$, primera parte, in fine: "Son autores quienes realizan el hecho por sí solos, conjuntamente o por medio de otro del que se sirve como instrumento." 
cooperación necesaria al suicidio valen los criterios que normalmente se manejan en relación con la cooperación necesaria como forma de participación en el delito.

En la cooperación al suicidio resulta, por tanto, especialmente relevante determinar si se trata de cooperación necesaria o no necesaria o complicidad, pues la no necesaria o complicidad es impune por atípica (en la teoría general de la participación también es importante la distinción, aunque la complicidad también es punible, pues la cooperación necesaria se castiga con la misma pena de la autoría -arts. 61 y 62 en relación con el art. 28 CP-, mientras que la no necesaria o complicidad se castiga con la pena inferior en grado a la que corresponde a la autoría -art. 63 en relación con el art. 29 CP; se ha de tener en todo caso en cuenta la excepción del art. 64 CP-). Los criterios para distinguir cooperación necesaria y complicidad vienen a coincidir en nuestro caso con los que generalmente se utilizan en la distinción; entre ellos, nos inclinamos por utilizar una combinación (en todo caso abierta y con detalles que aquí no se pueden matizar) de la teoría de los bienes y actividades escasos y del dominio funcional del hecho, sacado este último criterio (que supone un dominio meramente negativo) del ámbito de la autoría (que requiere, en nuestra opinión, dominio positivo) y llevado al terreno de la distinción entre dos formas de participación ${ }^{28}$.

Además de los supuestos de cooperación no necesaria o complicidad, que son atípicos, quedan también fuera del alcance del art. 143.2 CP aquellos casos de cooperación al suicidio que, aun siendo necesaria, reúnen los requisitos exigidos por el número 4 del art. 143 CP, donde se sancionan de modo más benigno algunas "conductas eutanásicas".

Si la frontera inferior de la cooperación necesaria al suicidio del art. 143.2 CP viene marcada por los actos de cooperación necesaria "eutanásica" al suicidio (más levemente penados) y por la cooperación no necesaria o complicidad al suicidio (impune), la superior vendría constituida por los supuestos de inducción (directa) al suicidio que podrían considerarse también "actos necesarios", pero que revisten una especial configuración y están sancionados (en general con pena más severa) en el número 1 del art. 143 CP, pero también y sobre todo (pues con la inducción se plantean menores problemas de delimitación) con los supuestos de autoría (de la clase que sea) de la muerte, es decir, de autoría de homicidio 0, en su caso, asesinato. Los criterios para decidir si estamos ante un supuesto de autoría son los manejados con carácter

28 V. una explicación más detallada en Miguel Díaz y García Conlledo, "Cooperación necesaria y complicidad", en EPB, 2002, pp. 311-318. Ampliamente sobre la figura de la cooperación necesaria, su distinción de la coautoría y de la complicidad o cooperación no necesaria, y defendiendo la conveniencia de su mantenimiento, aunque con otra formulación, Miguel Díaz y García Conlledo, "iEs necesaria la cooperación necesaria?" Libro-Homenaje al Prof. Dr. D. José Cerezo Mir, Comares, Granada, 2002, pp. 645-669, publicado en Argentina en: Revista de Derecho Penal 2005-2. Autoría y participación - II (Buenos Aires), pp. 125-160. 
general en la teoría de la autoría y la participación, siendo, en nuestra opinión, el más correcto el de la determinación positiva (o dominio positivo) del hecho ${ }^{29}$.

\subsubsection{Relevancia de la conducta omisiva en la cooperación}

Se discute si cabe cooperación omisiva al suicidio, existiendo diversas opiniones ${ }^{30}$. Creemos que la solución no debe diferir de la general que se mantenga para determinar cuándo existe participación por omisión, entendemos que tanto la doctrina mayoritaria de la posición de garante, como la que compartimos ${ }^{31}$ de que la omisión equivale a la acción positiva cuando es la propia omisión la que crea 0 aumenta (o hace que un riesgo controlado deje de estarlo) de forma decisiva o determinante el riesgo para el bien jurídico piensan en los supuestos de autoría; por tanto, de producirse lo anterior, estaríamos ante un supuesto de autoría de homicidio. En realidad, tanto para la autoría como para la participación, lo que tiene que suceder es que la omisión equivalga materialmente desde un punto de vista normativo a la comisión positiva. En la participación por omisión, ello significa que esta ha de suponer un favorecimiento, un levantamiento de obstáculos (no una mera no interposición de éstos) a la comisión del hecho (un hecho atípico, el suicidio) por el autor. Así, es difícil encontrar supuestos de cooperación por omisión al suicidio, máxime cuando, para que esta sea punible, ha de tratarse de cooperación necesaria.

Podría pensarse en castigar al que no impide el suicidio como autor de un delito de omisión de socorro, pero, en los casos de suicidio libre y responsable que aquí nos interesan, va a faltar el requisito de que el suicida sea una persona desamparada,

29 V. resumidamente, entre otros muchos trabajos, Miguel Díaz y García Conlledo, EPB, cit., pp. 145 ss.

30 Admiten las formas omisivas de cooperación: Francisco Muñoz Conde, Derecho Penal. Parte Especial, 18a , cit., pp. 64 s.; Agustín Jorge BarrelRo, Rodríguez Mourullo, Gonzalo (dir.) Comentarios al Código Penal, cit., p. 414; Juan Carlos Carbonell Mateu, Vives Antón, Tomás y otros, Derecho Penal. Parte Especial, Valencia, Tirant lo Blanch, 2008, p. 101; María del Carmen Gómez Rivero, "La intervención omisiva en el suicidio de un tercero" en Actualidad Penal 45, 1998, p. 902; Miguel Olmedo cardenete, Eutanasia, 2001, p. 140; Carmen Juanatey Dorado, PE, cit., pp. 71 s. Otro sector propugna la atipicidad de las formas omisivas en la actual redacción del CP con un argumento de orden gramatical, atendiendo a que el precepto tipifica expresamente tan sólo la conducta del tercero que coopere a través de actos necesarios al suicidio de una persona (art. 143.2) y la del que causa o coopera activamente con actos necesarios y directos a la muerte de otro en los supuestos de homicidio eutanásico (art. 143.4) y también atendiendo a la propia coherencia interna del precepto: José LuIS Dí́zZ Ripollés, José Luis/ Gracia Martín, Luis (coords.), Comentarios al Código Penal, cit., p. 217; Carlos Romeo Casabona, Los delitos contra la vida y la integridad personal y los relativos a la manipulación genética p. 105; entiende que el reconocimiento constitucional de la disponibilidad de la propia vida por uno mismo comporta ya la inexistencia o desaparición de la posición de garante por parte de terceros, cuando el interesado ha manifestado a esos terceros la decisión en ese sentido.

31 Más ampliamente Diego-Manuel Luzón PeñA, “La participación por omisión en la jurisprudencia reciente del TS" en Luzón Peña, Diego-Manuel: Estudios Penales, Barcelona, PPU, 1991, pp. 225-249. 
por lo que la omisión será impune ${ }^{32}$. Si se impide el suicidio, sin embargo, el posible delito de coacciones que podría parecer cometido estaría justificado por estado de necesidad. Y, aunque tampoco esto se aceptara, en los casos normales las reglas del error conducirían igualmente a la impunidad del que evita el suicidio ${ }^{33}$.

Si una persona induce al suicidio de otra y además coopera de manera necesaria en él, sólo será castigado, por regla general, como inductor (art. 143.1 CP), debiendo considerarse la cooperación necesaria como un acto posterior copenado o impune. Si quien induce al suicidio o coopera necesariamente en él realiza además una de las conductas del art. 143.3 CP, la calificación por este último delito será siempre preferente a la de cooperador necesario en el suicidio, y, en principio, también a la del inductor de este. Pero, dado el solapamiento de penas que se produce entre los números 1 y 2, por un lado, y 1 y 3, por otro, del art. $143 \mathrm{CP}$, puede suceder que en el caso concreto el acto de cooperación necesaria se considere más grave que el de inducción o que este resulte más grave que el encuadrable en el número 3 del artículo; en tales casos, habrá que optar por la calificación que implique mayor gravedad de la conducta (y, por tanto, de la pena) ${ }^{34}$.

\subsubsection{El resultado muerte del suicida y la tentativa}

En cuanto al papel que desempeña la muerte del suicida en estos delitos, la doctrina se halla dividida. Un grupo minoritario cree que la muerte no desempeña papel alguno y que el delito se consuma cuando se induce o coopera, con independencia de que el sujeto logre matarse 0 al menos lo intente. La doctrina mayoritaria ${ }^{35}$ y la jurisprudencia ${ }^{36}$ dan sin embargo relevancia a la muerte (o al intento) del suicida.

32 En igual sentido, Agustín Jorge BarreiRo, Rodríguez Mourullo, Gonzalo (dir.) Comentarios al Código Penal, cit., p. 414. De opinión contraria: Francisco Muñoz Conde, Derecho Penal. Parte Especial, 18. a , cit., p. 66; Miguel Olmedo cardenete, Eutanasia, cit., p. 145, quien sostiene que si se concibe al suicidio (como efectivamente hace) como un acto que, por regla general, puede considerarse como un comportamiento psíquicamente patológico y producto de un grave conflicto emocional interno, entonces cabrá defender también para estos casos la presencia de un deber genérico de auxilio y la correlativa responsabilidad por el art. $195 \mathrm{CP}$ si se infringe el mismo, circunstancia que correlativamente obliga a negar la responsabilidad criminal por el delito o falta de coacciones, por parte de quien impide al suicida la causación de su propia muerte.

33 V. un tratamiento detallado de las distintas alternativas en Gisele Mendes de CARvalho, Suicidio, eutanasia y Derecho Penal, cit., pp. 257-267.

34 En este sentido, ya en Miguel Díaz y García Conlledo, EPB, cit., pp. 769 s.

35 V. por muchos, José Luis Díez Ripolésé, José Luis/Gracia Martín, Luis (coords.), Comentarios al Código Penal, cit., p. 199, Francisco Muñoz Conde, Derecho Penal. Parte Especial, 18a, cit., pp. 64 s.; Carmen Tomás-Valiente Lanuza, La cooperación al suicidio y la eutanasia en el nuevo CP (art.143), cit., pp. 54 s.

36 Un análisis de la escasa jurisprudencia existente acerca de las conductas relacionadas con el suicidio, en Jesús Toledano Toledano, Límites penales a la disponibilidad de la propia vida, cit., pp. 230-243. 
Consideramos acertada esta segunda posición, por diversas razones, entre las que destacaremos que el adelanto de la consumación a fases previas a la producción del resultado (en los delitos de resultado) es excepcional en el CP; que, para que la participación sea punible como tal (con carácter general), es necesario que el autor dé comienzo a la ejecución del hecho; y que, de seguirse la otra postura, resultaría penada la inducción o cooperación necesaria a un suicidio ni siquiera intentado, mientras que la cooperación necesaria a un homicidio ni siquiera intentado será impune (salvo que constituya algún caso de conspiración) y la inducción a un homicidio intentado sólo podrá castigarse como proposición (para quienes lo admiten) ${ }^{37}$; y, además, la inducción a un suicidio meramente intentado podría llegar a castigarse en algunos casos con pena superior (prisión de cuatro a ocho años) a la que corresponde a la inducción a un homicidio que queda en grado de tentativa (la inferior en uno o dos grados a la del delito consumado, dependiendo de ciertas circunstancias -art. 62 CP-, o sea, prisión de cinco a diez años si se rebaja la pena en un grado, pero prisión de dos años y seis meses a cinco años si se rebaja en dos).

Pero también esta posición mayoritaria se divide a la hora de considerar la naturaleza de la muerte: para unos se trata de una condición objetiva de punibilidad ${ }^{38}$, por lo que no necesitaría ser abarcada por el dolo del partícipe en el suicidio y por lo que, si no se da, excluiría totalmente la punibilidad de la conducta, aun cuando el suicidio se hubiera intentado. Para otro sector doctrinal, en nuestra opinión más acertado (pues la conducta inductora 0 auxiliadora tiene influencia en la muerte y los elementos del tipo se refieren a menudo a hechos no prohibidos, como es en este caso el suicidio, para describir la conducta penalmente prohibida), la muerte del suicida es un elemento típico del delito y, como tal, ha de ser abarcado por el dolo del inductor 0 auxiliador $y$, de no producirse, pero haberse intentado el suicidio, daría lugar a responsabilidad del inductor 0 auxiliador por tentativa del delito del correspondiente número del art. 143 СР9.

37 Más detalladamente en Miguel Díaz y García Conlledo, "Conspiración, proposición y provocación", en EPB, 2002, pp. 299-310; Soledad Barber Burusco, Los actos preparatorios del delito, Granada, Comares, 2004, pp. 201 ss.

38 Ánget Torío López, Homenaje a D. Ignacio Serrano y Serrano, cit., pp. 653 ss.; Alfonso SerRano Gómez, / Alfonso Serrano Maíllo, Derecho Penal. Parte Especial, 16ª ed., Madrid, Dykinson, 2011, p. 52.

39 La admisibilidad de la tentativa se encuentra debatida, no sólo por quienes entienden que la muerte es una condición objetiva de punibilidad, sino también por quienes acudiendo a argumentos teleológicos y político-criminales sostienen que la excepcionalidad que supone el castigo autónomo de actos de participación en un hecho principal impune debe compensarse con una interpretación estricta del ámbito de la punición respecto de unas conductas que no son más que participación en el ejercicio del libre desarrollo personal del autor principal: Bernado Del Rosal Blasco, ADPCP, 1987, pp. 92-94. Estima admisible sólo la tentativa acabada Carmen Juanatey Dorado, PE, cit., p. 70; para José Luis Díez Ripoltés, Díez Ripollés José Luis/Gracia Martín, Luis (coords.), Comentarios al Código Penal, I cit., p. 


\subsubsection{Participación en la inducción y en la cooperación al suicidio}

Consideramos que cabe participación punible ${ }^{40}$ (siempre que sea dolosa y reúna ciertas características) en la inducción o la cooperación necesaria al suicidio, lo que se puede fundamentar al menos de dos modos. Una primera fundamentación aduciría que en los números 1 y 2 del art. 143 CP nos hallamos ante formas de participación convertidas en tipo autónomo 0 , si se quiere, de autoría, aplicándose por tanto las reglas generales de la participación a quienes intervienen en el hecho del inductor 0 cooperador necesario al suicidio. Esta primera solución supondría que, en principio, sería punible (aunque con la pena inferior en grado a la del inductor o el cooperador necesario -art. 63 (P-) incluso la complicidad con el inductor o cooperador necesario al suicidio, y que la pena del partícipe dependerá de si colabora con un inductor o con un cooperador necesario y no de la influencia de su colaboración en el propio suicidio.

Todo ello se podría sostener sobre la base de que el fundamento del castigo del partícipe es el fomento del hecho principal delictivo, o sea (desde esta perspectiva) el hecho de inducción o cooperación necesaria al suicidio. Pero, aun así, entendemos que el castigo de la participación de la participación en el suicidio constituye un supuesto especial que ni es idéntico a otras formas de participación (pues no lo es en un hecho típico) ni tampoco a las de autoría (porque su modus operandi es el de la participación); en definitiva, la finalidad de la ley parece ser castigar ciertas formas especialmente graves (y dependiendo además de su influencia en la decisión del suicida) de fomento de un hecho atípico como es el suicidio, y el castigo de la participación en esas formas de fomento no debería suponer la ampliación de la punición a supuestos que, en definitiva, no suponen a su vez el mismo grado de fomento del suicidio que las primeras. Es decir que la excepcionalidad del supuesto da a entender que lo fundamental es la influencia de cualquier conducta en el suicidio para determinar su castigo o impunidad. Por ello entendemos que, incluso desde la primera argumentación que hemos visto, se debería realizar una interpretación restrictiva que excluyera de la punición las formas de

211, razones teleológicas permiten concluir la impunidad de la tentativa acabada e inacabada de inducción al suicidio. Admiten la punibilidad de la tentativa tanto en los supuestos de inducción como de cooperación Carlos Romeo Casabona, Los delitos contra la vida, cit., p. 117; Agustín Jorge Barreiro, Rodríguez Mourullo, Gonzalo (dir.) Comentarios al Código Penal, cit., p. 415, Juan Carlos Carbonell Mateu, Vives Antón, Tomás y otros, Derecho Penal. Parte Especial, cit., p. 94; Francisco Muñoz Conde, Derecho Penal. Parte Especial, 18a, cit., p. 68. Jesús Toledano Toledano, Límites penales a la disponibilidad de la propia vida, cit., pp. $180 \mathrm{~s}$.

40 También, como en las formas imperfectas de ejecución, la admisibilidad de la participación se discute, resultando rechazada por un amplio sector; así, por ejemplo, para José LuIs Díez Ripoltés, Díez Ripollés Luis/Gracia Martín, Luis (coords.), Comentarios al Código Penal, cit., p. 212, razones teleológicas similares a las que le conducen a descartar el castigo de la tentativa: la naturaleza excepcional del castigo autónomo de formas de participación, unida a que tales participaciones acaban en una contribución a un hecho vinculado al ejercicio por uno mismo del derecho a la disponibilidad de la propia vida, aconsejan hacer una interpretación restrictiva y declarar la impunidad. 
complicidad (cooperación no necesaria) con el inductor o el cooperador necesario en el suicidio. Sin embargo, otra posibilidad interpretativa en el sentido de excluir del castigo toda forma de participación en la inducción o cooperación necesaria en el suicidio tampoco nos parece convincente, pues dejaría impunes algunas intervenciones de influencia decisiva (aunque no directamente ejercidas sobre el suicida) en el suicidio.

Por todo lo dicho, nos parece preferible una segunda vía de fundamentación de la punibilidad de ciertas formas de participación en la inducción y la cooperación necesaria al suicidio: esas formas de participación sólo serán punibles en cuanto a su vez constituyan inducción (cosa difícil, si no imposible de imaginar) o cooperación necesaria al suicidio (en definitiva, se está aplicando la idea de que la participación en cadena debe castigarse en cuanto participación en el hecho principal y no en el del partícipe, si bien es verdad que aquí, si se identifica el "hecho principal" con el suicidio, estaríamos llamando hecho principal a un hecho atípico; pero, pese a todo, se puede decir que el suicidio es el hecho central en estos delitos en tanto en cuanto es el suicida el que domina o determina el suceso). De este modo se atiende mejor al telos de la ley cuando castiga la participación en el suicidio, quedando excluida la punición de la complicidad con el inductor o el cooperador necesario (que, a lo sumo, constituirá complicidad -impune- en el suicidio). Por otro lado, como no parece posible pensar en conductas que supongan inducción al suicidio, las formas de participación en la inducción o la cooperación necesaria al suicidio se castigarán, cuando resulten necesarias para el suicidio, a través del art. $143.2 \mathrm{CP}$, que prevé una pena inferior (salvo excepciones en el caso concreto) a la del art. 143.1 (esto es importante, pues, por ejemplo, la inducción a la inducción al suicidio no se castigará como inducción al suicidio -en la primera fundamentación vista al inductor del inductor al suicidio le correspondía un marco penal igual al de éste-, sino como cooperación necesaria a él, $y$, por tanto, con una pena inferior a la del inductor al suicidio) ${ }^{41}$.

\subsection{El homicidio consentido y la cooperación ejecutiva al suicidio}

El inciso 3 del art. 143 dispone que "Será castigado con la pena de prisión de seis a diez años si la cooperación llegara hasta el punto de ejecutar la muerte"42.

41 En este sentido, ya en Miguel Díaz y García Conlledo, EPB, cit., pp. 771 s.

42 El precedente inmediato en la legislación española de este precepto es el párrafo final del art. 409 CP 1944/73. Un sector importante entendía que la figura, denominada también homicidio-suicidio, contenida en este precepto era la del homicidio consentido, que la ley castigaba con la misma pena que el homicidio, aunque suponía un privilegio (por la existencia de consentimiento) frente a los tipos más graves del hoy inexistente parricidio y del asesinato. Otro sector sostenía que seguía habiendo suicidio y una intervención especialmente grave en él (casos de dominio compartido entre el suicida y el interviniente, o, casos de cooperación ejecutiva al suicidio: V. Miguel Díaz y García Conlledo, EPB, cit., p. 3332). En cualquier caso, la polémica no tenía excesiva trascendencia práctica, al castigarse la figura con la misma pena del homicidio. 
La palabra "cooperación", empleada en el texto legal, evoca la idea de participación y, sobre todo, parece que hay que relacionarla con la utilizada en el número 2 del mismo art. 143 que habla del "que coopere con actos necesarios al suicidio de otra persona". Por lo tanto, tendría que haber suicidio, es decir, que el autor de la muerte fuera la propia persona que va a morir (y el mero consentir su muerte no supone, en nuestra opinión, autoría de la misma y suicidio ${ }^{43}$, siendo partícipe en ella el cooperador ejecutivo (y pudiendo incluirse en el art. 143.3 también al tercero que compartiera el dominio del hecho con el suicida en este precepto, pues, aunque encajaría en la coautoría de un homicidio consentido, también supondría cooperación ejecutiva en la conducta del suicida, resolviéndose el concurso de leyes o de normas a favor de esta última calificación). Incluso podría sostenerse que el art. 143.3 es un subtipo más grave que el del art. 143.2; este castigaría la cooperación necesaria al suicidio y aquel -más gravemente- la cooperación necesaria al suicidio prestada mediante actos ejecutivos. El homicidio consentido se castigaría como homicidio en el art. $138 \mathrm{CP}$, teniendo la existencia de consentimiento probablemente la virtualidad fundamental de excluir (al menos en la mayoría de los casos) la aplicación del tipo más grave de asesinato (pudiendo apreciarse en su caso circunstancias modificativas genéricas). A toda esta argumentación podría oponérsele que en el vigente CP la cooperación ejecutiva no se menciona como forma general de participación en los arts. 28 o 29 (al contrario de lo que, para un sector doctrinal, sucedía en el anterior CP, cuyo art. 14.1 la recogía). Se argumentaría que se inventa una forma de participación, inexistente en el CP, para explicar esta figura del art. 143.3 CP. Pero esta consideración carece de peso, pues que el CP no se refiera a la cooperación ejecutiva específicamente en los preceptos generales sobre autoría y participación no hace que la misma desaparezca de la realidad como una forma más de cooperación (seguramente siempre necesaria) de aquella a la que el CP sí se refiere en esos preceptos. Y es perfectamente posible (aunque pueda no compartirse la idea) que en materia de participación en el suicidio el CP distinga, a la hora de castigar con menor o mayor severidad, entre diversas formas de cooperación (necesaria no ejecutiva y ejecutiva), aunque no lo haga en los preceptos generales relativos a la participación en el delito, del mismo modo que en ellos iguala la pena de la inducción y la cooperación necesaria y no lo hace en el caso de la inducción y la cooperación necesaria al suicidio, o del mismo modo que considera punible con carácter general la complicidad al delito e impune la complicidad al suicidio ${ }^{44}$.

Pero, si la anterior fuera la única posibilidad interpretativa, se producirían importantes consecuencias prácticas. El art. 143.3 CP prevé una pena de prisión de seis

43 Aunque, como ya hemos expresado, otro sector de la doctrina define el suicidio de forma diferente, v. supra apartado 2.

44 En este sentido, ya en Miguel Díaz y García Conlledo, EPB, cit., p. 773. 
a diez años, mientras que el art. 138 CP establece para el homicidio (donde encajaría el consentido) una pena de prisión de diez a quince años. Quizá podría sostenerse que la presencia del consentimiento conducirá en la práctica a la imposición del mínimo de esta pena y, por tanto, la diferencia no sería tan grande; pero, aparte de que la pena sigue siendo muy diferente (el límite mínimo del art. 143.3 CP es de seis años), la referencia a la imposición del mínimo en la práctica es insegura. Como la cuestión de qué es lo que se castiga en el art. $143.3 \mathrm{CP}$ es muy discutida ${ }^{45}$ y no está claro que el homicidio consentido resulte merecedor de una pena mucho más severa que la cooperación ejecutiva al suicidio, conviene indagar la posibilidad interpretativa de incluir en el art. 143.3 CP el homicidio consentido.

Desde luego, el tenor literal no facilita esa interpretación, si bien se podría intentar leer ampliamente la palabra "cooperación" e incluso "suicidio" (palabra que, por otro lado, no se emplea en el número 3 del art. 143 CP, aunque hay una bastante clara referencia a su uso en el número anterior), teniendo en cuenta que se trata de una interpretación pro libertate, que favorece a los posibles autores de homicidios consentidos. Pero es que, además, existe un argumento sistemático que favorece esa interpretación: el número 4 del art. 143 CP, referente a ciertas conductas eutanásicas, pese a sus defectos de redacción parece claramente referirse a supuestos de homicidio eutanásico (eutanasia activa directa), junto a otros de cooperación necesaria, y hace referencia expresa, al establecer la pena, a los números 2 y 3 del mismo artículo, es decir, también al que ahora analizamos. Podría argumentarse que se trata de una mera referencia penológica y no de que la propia ley parte (en el número 4) de la idea de que en el número 3 se contienen homicidios consentidos (aunque probablemente lo hace); pero, aun así, resultaría extraño desde un punto de vista valorativo que la ley entienda que es mucho más grave un homicidio consentido (art. $138 \mathrm{CP}$ ) que una cooperación ejecutiva en un suicidio (art. 143.3 CP) y sin embargo los iguale cuando se dan las condiciones (propias de la eutanasia) del art. 143.4 CP (que sin embargo, sigue distinguiéndolos de los actos de cooperación necesaria).

En consecuencia, dadas las dudas interpretativas que suscita el art. $143.3 \mathrm{CP}$ y los argumentos que se acaban de exponer, parece preferible, pese a las dificultades que plantea su tenor literal, optar por una interpretación más benigna que incluya en él el homicidio consentido ${ }^{46}$, aunque también la cooperación ejecutiva al suici-

45 V. una exposición del debate en: Carmen Tomás-Valiente LAnuza, La cooperación al suicidio y la eutanasia en el nuevo CP (art.143), cit., pp. 91-100.

46 Considera que no estamos ante una modalidad de homicidio consentido Agustín Jorge BarRelro, Rodríguez Mourullo, Gonzalo (dir.) Comentarios al Código Penal, cit., p. 415. En el sentido de incluir el homicidio consentido, pero sólo este supuesto, se pronuncia José Luis DíEz Ripollés, Díez Ripollés José Luis/Gracia Martín, Luis (coords.), Comentarios al Código Penal, cit., pp. 196 s., quien sostiene que lo que da unidad al art. 143 es el concepto suicida, implícito en todos los párrafos, pero no la noción de suicidio que sólo 
dio ${ }^{47}$ (que, de no aceptarse su inclusión aquí, habría que entender comprendida en el número 2 del artículo que nos ocupa). Quedan entonces incluidos en ese precepto los supuestos de dominio compartido o conjunto (0, en nuestra terminología, determinación compartida o conjunta) del hecho entre el tercero y el suicida y los supuestos de homicidio a petición de la víctima, siempre y cuando, en estos y en los demás casos de homicidio consentido y cooperación ejecutiva al suicidio, no concurran las características propias de la eutanasia que recoge el art. 143.4 CP48.

Por lo demás, la inclusión del homicidio consentido en el número 3 del art. 143 CP (en vez de en el 138), podría tener relevancia en cuanto a determinar si ese homicidio consentido es susceptible de encubrimiento o favorecimiento personal del art. $451.3^{\circ}$ a) CP.

\subsection{La eutanasia}

El CP establece en su art. 143.4 que “El que causare o cooperare activamente con actos necesarios y directos a la muerte de otro, por la petición expresa, seria e inequívoca de éste, en el caso de que la víctima sufriera una enfermedad grave que conduciría necesariamente a su muerte, o que produjera graves padecimientos permanentes y difíciles de soportar, será castigado con la pena inferior en uno o dos grados a las señaladas en los números 2 y 3 de este artículo".

Requisito esencial es la situación de enfermedad que se señala ly que se aproxima bastante a la descripción general de la situación propia de la eutanasia antes realizada) y la existencia de una petición expresa, seria e inequívoca del que quiere morir (que deberá desde luego poseer una capacidad suficiente para realizarla). La gravedad de la enfermedad y de los padecimientos permanentes y la dificultad de soportarlos suponen conceptos bastante indeterminados, en los que habrá que tener

está presente en el art. 143. 1 y 3. Juan José González Rus, PE, cit., p. 101, considera incluido el homicidio solicitado o a petición; Miguel Ángel Núñez Paz, Homicidio consentido, eutanasia y derecho a morir con dignidad, cit., pp. 385 ss.; Carmen Tomás-Valente Lanuza, La cooperación al suicidio y la eutanasia en el nuevo CP (art.143), cit., p. 100; Carlos Romeo CASABona, Los delitos contra la vida y la integridad personal y los relativos a la manipulación genética p. 113, considera que el inciso acoge hipótesis diversas y dogmáticamente apenas compatibles entre si. Se superpone y sucede temporalmente en la cooperación ejecutiva al suicidio un complejo entramado de verdaderos elementos de autoría $-y$ ocasionalmente de coautoría- y de participación. Considera relevante retener que la acción típica del art. 143.3 se enmarca en el suicidio de otro, y puesto el suicida se pone en manos del ejecutor para que dé cumplimiento a su designio de quitarse la vida. F. Javier Álvarez García, Álvarez García, F. Javier, (Dir) Derecho Penal Español, Parte Especial, cit., p. 100, afirma que este precepto recoge un supuesto de homicidio atendiendo, fundamentalmente, a que la sanción prevista claramente se aleja de la que amenaza a la cooperación.

47 Incluye solamente la cooperación ejecutiva al suicidio Francisco Muñoz Conde, Derecho Penal. Parte Especial, 18ª cit., p. 68, pero no efectúa mayores precisiones.

48 En este sentido, ya en Miguel Díaz y García Conlledo, EPB, cit., p. 774. 
en cuenta ciertos estándares y dictámenes concretos médicos, no olvidando que el dolor y la capacidad de soportarlo son en buena medida subjetivos (aunque parece claro que el CP no pretende una subjetivización total de esos conceptos). Por tanto, se produce cierta inseguridad, pero la finalidad de la ley parece ser restringir bastante los supuestos ${ }^{49}$.

La exigencia de que la petición sea expresa e inequívoca es restrictiva ${ }^{50}$; quizá hubiera sido suficiente con exigir lo segundo (además de que sea seria y emitida por persona capaz), pues si una petición es inequívoca no se ve qué importancia tiene que sea expresa; en cualquier caso, se muestra aquí el celo -para algunos "recelo"- del legislador por evitar el privilegio en situaciones de duda en una cuestión muy delicada y que puede prestarse a abusos.

La redacción del precepto es poco clara porque admite diversas interpretaciones: dado que "causare" puede referirse a la realización de la muerte como autor (aunque en puridad también otros intervinientes, partícipes causan), el adjetivo los "actos necesarios" parece claramente referido sólo a la cooperación, pareciendo por tanto que también el "directos" está sólo referido a esta, sin entenderse muy

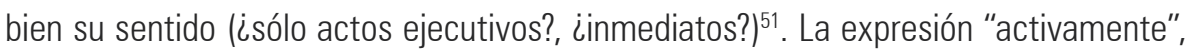
que podría ir referida tanto a la conducta de causar como a la de cooperar, podría interpretarse como exclusión de las conductas omisivas, también las de comisión por omisión (y sin abarcar las de omisión por hacer). Probablemente esta falta de claridad se deriva de la adopción por el CP (eso sí, sin hablar abiertamente de eutanasia) de la terminología comúnmente empleada en la clasificación de la eutanasia, a cuyo carácter equívoco ya hemos aludido anteriormente.

Por ello, en una interpretación teleológica que nos parece la más sensata posible y, en este caso casi coincidente con la voluntad del legislador histórico, conviene interpretar que con la introducción del adverbio "activamente" se ha querido excluir

49 Críticos con la imprecisión del los términos empleados por el legislador: Agustín JoRge BarReiro, Rodríguez Mourullo, Gonzalo (dir.) Comentarios al Código Penal, cit., p. 418; Miguel Díaz y García Conlledo, EPB, cit., p. 776. Por el contrario, Jesús Barouín Sanz, "La eutanasia como forma de intervención en la muerte de otro" en Eutanasia y suicidio. Cuestiones dogmáticas y de política criminal, Granada, Comares, 2001, pp. 155-211, pp. 178 s., la considera un acierto, atendiendo a la variedad de supuestos en los que el sufrimiento de una persona impedida puede resultar insoportable para ella misma es incompatible con el empleo de una fórmula cerrada en su regulación.

50 Valora positivamente que se añadan cautelas especiales a la exigencia del consentimiento, Jesús Barouín Sanz, Jesús, “La eutanasia como forma de intervención en la muerte de otro”, cit., 2001, p. 172.

51 Mirentxu Corcoy Bidasolo, Autonomía personal, 2010, p. 313, considera que la exigencia podría estar relacionada con los problemas político-criminales que suscita la prueba de la existencia de un consentimiento en estos supuestos, pareciendo que debe entenderse que el legislador trata de obligar al titular del derecho a que ejercite personalmente su derecho a disponer de él, sin que pueda trasladar la decisión última a un tercero. 
140 Participación en el suicidio y eutanasia. Esbozo del tratamiento penal en España -

Miguel Díaz y García Conlledo - Soledad Barber Burusco

de este tipo el castigo de la eutanasia pasiva (en la cual han de incluirse también los supuestos de omisión por hacer) y abarcar los de eutanasia activa (en los que deberían incluirse posibles supuestos de comisión por omisión). Ello es además un claro indicio de que el CP se pronuncia por la impunidad de la eutanasia pasiva; está claro que no deja fuera de este precepto esa forma de eutanasia para excluirla del privilegio (resultaría absurdo), aunque tampoco se pronuncia expresamente sobre si esa modalidad de eutanasia podría constituir omisión de socorro (art. 195 CP), si bien en una eutanasia pasiva faltará el elemento típico de tratarse de una persona desamparada. Siguiendo esta línea de interpretación, el adjetivo "directos" seguramente intenta dejar fuera del ámbito del derecho penal la eutanasia activa indirecta, que también resultaría atípica (no nos pronunciamos sobre la cuestión de la posible responsabilidad -tampoco sobre su índole- que pudiera generar la negativa de un tratamiento paliativo cuando se acorta sensiblemente la vida). Por tanto, de una forma algo enrevesada y confusa, en sus resultados de impunidad de la eutanasia pasiva y la activa indirecta viene a coincidir con la interpretación propugnada cuando en la legislación española no se había incorporado aún este precepto ${ }^{52}$.

El privilegio que supone (por tratarse de casos relacionados con la eutanasia) el art. 143.4 CP se extiende a dos supuestos. El primero es el de la causación de la muerte, que parece ir referido al homicidio a petición (en las condiciones vistas) -los supuestos claros de eutanasia activa directa-, aunque, si la cooperación ejecutiva en el suicidio (como algo distinto al homicidio consentido) se entiende incluida en el número 3 del art. 143 CP, también alcanzaría a esta, cuando se realice a petición de la víctima y en las condiciones que conocemos. En estos casos corresponderá la pena inferior en uno (prisión de tres a seis años) o dos (prisión de un año y seis meses a tres años; en este caso, cuando la pena resulte inferior a dos años, podrá plantearse la suspensión de su ejecución) grados a la señalada en el art. 143.3 CP, sin que se apunten criterios específicos para decidir el quantum de la rebaja.

El segundo supuesto es el de la cooperación necesaria a petición. El texto del precepto no aclara si se refiere a la cooperación necesaria en un suicidio (en que se da la situación eutanásica vista) a petición del suicida 0 a la cooperación necesaria con quien realiza la eutanasia activa, aunque la remisión al fijar la pena al número 2 del art. 143 CP parece apuntar más a la primera situación. No obstante, creemos que debe entenderse comprendida también la segunda, dado el carácter amplio de la redacción legal ("cooperar con actos necesarios ... a la muerte de otro"); de lo contrario, el cooperador necesario con quien practica la eutanasia activa directa debería responder, según las reglas generales, con la misma pena que este, es decir con la inferior en uno 0 dos grados a la del art. 143.3 CP ly no, como consideramos preferible, con la

V. Miguel Díaz y García Conlledo, EPB, cit., p. 3335. 
inferior en uno o dos grados a la del 143.2 CP). Aunque sólo fuera por lo dudoso de la cuestión (aunque también por razones de la teleología del precepto), creemos que debería optarse por la solución más benigna señalada. La pena correspondiente es la inferior en uno (prisión de uno a dos años) o dos (prisión de seis meses a un año) grados a la del número 2 del art. $143 \mathrm{CP}$, sin que tampoco se expresen criterios específicos para determinar la rebaja. En este supuesto es especialmente importante la posibilidad de suspender la ejecución de la pena 0, cuando no exceda de un año, la de sustituirla por otra.

En cuanto a la complicidad (cooperación no necesaria) a petición (y en las condiciones señaladas) en un suicidio, no cabe duda de su atipicidad, pues, aparte de no mencionarse en el número 4 que analizamos, sabemos que la complicidad en el suicidio, aun sin los requisitos del tipo privilegiado, es atípica. Se podría plantear si esta atipicidad alcanza también al cómplice de quien practica como autor una eutanasia activa directa (a petición y con todos los requisitos conocidos). Aunque podría apoyarse con algún argumento su responsabilidad conforme a las normas generales (es decir, pena inferior en un grado a la del autor, que a su vez es inferior en uno 0 dos grados a la del art. 143.3 CP), el telos del precepto analizado y, en general, de todo el art. $143 \mathrm{CP}$ nos inclina a interpretar que la complicidad en este caso resulta impune. Esta solución es además la única sistemática y valorativamente coherente con la también realizada de que la cooperación necesaria a que se refiere el tipo privilegiado es también la cooperación necesaria con el autor del homicidio eutanásico a petición, pues, de lo contrario, al cómplice le correspondería una pena superior a la de este cooperador necesario.

Sin embargo, no es impune, sino que simplemente no le alcanza el privilegio del art. 143.4 CP y será castigada conforme al número 1 de ese artículo, la inducción al suicidio de una persona que se encuentre en la situación de enfermedad y padecimiento descrita en el tipo privilegiado, pues la inducción al suicidio es incompatible con la petición del que quiere morir y, en todo caso, la ley no privilegia ninguna conducta que haga surgir en el enfermo la decisión de morir (matándose o matándolo un tercero). Distinta es la cuestión de la responsabilidad de quien induce a un tercero a matar a un enfermo de las características vistas cuando éste lo solicita (el caso puede resultar extraño, pero no lo es tanto: un enfermo de las características vistas le pide expresa, seria e inequívocamente a un amigo que le quite la vida o consiga que alguien se la quite; el amigo acude a un médico conocido suyo y le pide que practique la eutanasia, como efectivamente hace). En este caso, creemos que el inductor responderá según las reglas generales, es decir, con la misma pena del autor, o sea, la del tipo privilegiado, en concreto la inferior en uno o dos grados a la del art. 143.3 CP. De este modo, le alcanza el privilegio, lo cual es lógico, pues él no ha hecho surgir en el enfermo la resolución 
de quitarse o que le quiten la vida; es más, cabría, forzando la argumentación, incluso una solución más generosa (aunque más dudosa) para este inductor: entender que ha actuado como cooperador necesario a petición en la muerte, con lo que, según lo dicho anteriormente, respondería con la pena inferior en uno o dos grados a la del art. 143.2 CP. Esta pena es la que, en todo caso, corresponderá al inductor de un cooperador necesario en un suicidio o en un homicidio eutanásico.

Entendemos que en cualquiera de los supuestos típicos del art. 143.4 cabrá apreciar además, en su caso, la atenuación en virtud de los móviles que guían a sujeto.

La técnica del art. 143.4 CP no es, como se ha visto, demasiado depurada, se echa de menos una mayor claridad y, en este sentido, se puede criticar el precepto.

En cuanto a las consecuencias a que conduce en relación con el castigo de la eutanasia entendemos que los resultados no distan demasiado de los que se podían obtener con la anterior legislación mediante la aplicación de las figuras generales, en especial, para la eutanasia activa directa, el estado de necesidad incompleto (también coincidía el resultado de impunidad de la eutanasia pasiva y la activa indirecta) ${ }^{53}$. Probablemente, la contemplación expresa en el CP de estas conductas evita la duda y el rechazo que algún autor pueda manifestar frente a las construcciones restrictivas del castigo con las categorías generales y aclara (en el sentido de que no nos encontramos ante un homicidio común y, ni siquiera, ante cualquier homicidio consentido, ni ante cualquier cooperación necesaria al suicidio) la cuestión para la jurisprudencia.

Un importante sector doctrinal considera que con la incorporación de la regulación de la eutanasia activa directa al CP con una pena atenuada, el legislador ha adoptado una posición definitiva con respecto a la posibilidad de aplicación de una eximente completa por estado de necesidad, porque, al optar por la previsión de una mera atenuación de la pena para los supuestos de eutanasia regulados en el art. 143.4 CP, ha querido indicar que la posibilidad de despenalización total ha quedado negativamente saldada por la nueva regulación ${ }^{54}$. Aun sin pronunciarnos definitivamente acerca de

53 V. Miguel Díaz y García Conlledo, EPB, cit., p. 3335.

54 Enrique Gimbernat Ordelg, Prólogo a la segunda edición del Código Penal, 17a , Madrid, Tecnos, 2011, pp. 61 s., afirma que el CP al describir expresamente supuestos eutanásicos, no para descriminalizarlos, sino para aclarar que son punibles (castigando expresamente la eutanasia activa) supone una regresión frente a la situación anterior, atendiendo al hecho de que la ciencia española había aportado argumentos muy sólidos para fundamentar que esa clase de "homicidio piadoso" era impune, sin que hasta el momento los tribunales hubieran tenido ocasión de pronunciarse sobre esa opinión doctrinal. CARMEN Tomás-Valente Lanuza, La cooperación al suicidio y la eutanasia en el nuevo CP (art.143), cit., p. 105, más contundentemente afirma que la previsión expresa de una causa de justificación incompleta en el art. 143.4 CP precluye la aplicabilidad de la causa de justificación genérica del estado de necesidad porque el legislador ya se ha planteado el específico conflicto de intereses inherente a las situaciones objeto del art. 143.4 y ha optado por resolverlo en el sentido de que no pasa por la plena justificación y la consecución de esta última merced a la apreciación de un estado de necesidad genérico supone desvirtuar la decisión expresamente adoptada por el legislador democrático. Carmen Juanatey Dorado, 
que pueda entenderse que la ley recoge (como afirma la mayoría de la doctrina ${ }^{55}$ ) supuestos de justificación incompleta (un caso específico de estado de necesidad incompleto), consideramos que nada impide que en supuestos excepcionales (como lo son, por otra parte, todos los que pueden terminar enmarcándose en una causa de justificación completa o incompleta), dados los requisitos típicos previstos en el art. 143.4 CP, se presente, para el autor del hecho, un conflicto de intereses que permita justificar parcialmente 0 , incluso, totalmente la conducta eutanásica ${ }^{56}$. No es el legislador el que ha vedado la posibilidad de aplicar una causa de justificación al legislar tal y como lo hizo (esto no lo dice en ningún sitio); lo que veda esta posible aplicación es la consecuencia asignada a una interpretación doctrinal acerca de la naturaleza jurídica del nuevo precepto. De generalizar la lógica contenida en esa interpretación, cada vez que el legislador privilegie una conducta respecto de la cual pudiéramos interpretar que ha efectuado una ponderación de intereses, deberíamos sostener que determinadas causas de justificación no resultan aplicables si se realizan conductas que encajen en esos preceptos. Cuestión distinta, y que resulta aceptable, es la afirmación de que si la jurisprudencia se tuviera que enfrentar con hechos que hoy deben subsumirse en el art. 143.4 CP, de no existir este, tal vez, hubiera resuelto la cuestión aplicando una causa de justificación completa o incompleta. Entendemos que nada impide tampoco que, dadas determinadas circunstancias o condiciones en el autor del hecho, se admita la concurrencia de una inexigibilidad individual que disminuya o le exima de culpabilidad.

\subsubsection{Algunas propuestas de regulación}

De todos modos, la incorporación legislativa relativa a la eutanasia que acabamos de analizar no ha acallado el debate que (al igual que en otros muchos países) existe

$P E$, cit., p. 74, en el mismo sentido, afirma que "el problema es que al castigar expresamente estos supuestos, el legislador impide la apreciación de la justificación de los mismos, en virtud de lo dispuesto en el artículo $20 \mathrm{CP}$, conforme se venía propugnando por un importante sector de la doctrina española". Gisele Mendes de Carvalho, Suicidio, eutanasia y Derecho Penal, cit., pp.305 ss., recoge exhaustivamente las opiniones de estos y otros autores y también sostiene que "al menos, de lege lata la despenalización total ha quedado negativamente saldada por la nueva regulación".

55 Se aleja de esta opinión Carlos Romeo Casabona, Los delitos contra la vida y la integridad personal y los relativos a la manipulación genética, cit., p. 126. Considera que el tratamiento privilegiado de este tipo se basa sobre todo en el menor reproche de la conducta del sujeto que actúa bajo los presupuestos típicos que menciona el art. 143.4 CP.

56 Aluden a la posible aplicación de una causa de justificación: José Luis Díez Ripoltés, Díez Ripollés José Luis/Gracia Martín, Luis (coords.), Comentarios al Código Penal, cit., p. 244; Mıguel Ángel Núñez Paz, Homicidio consentido, eutanasia y derecho a morir con dignidad, cit., p. 436; Francisco Muñoz Conde, Derecho Penal. Parte Especial, 18ª cit., p. 72. V. también los argumentos de Diego-Manuel Luzón Peña, Estudios Penales, 1991, pp. 329 ss., en relación a las indicaciones en el aborto. 
sobre la misma. Tanto antes como con posterioridad a la incorporación del art. 143.4 CP se han presentado en nuestro país propuestas para despenalizar ciertos supuestos eutanásicos. Ya en el año 1993 el Grupo de Política Criminal57 presentó una propuesta alternativa al tratamiento jurídico de las conductas de terceros relativas a la disponibilidad de la propia vida, que contenía una propuesta de reforma de la Ley General de Sanidad, de la Ley de Regulación del Contrato de Seguro y del CP 1994/73 entonces vigente, en la que, además de ciertas modificaciones relacionadas con la atenuación de la pena relacionadas con la inducción, la cooperación y la ejecución activa de la muerte de otro (exigiendo que quien lo solicite sea mayor de 18 años y con capacidad natural de juicio), proponía la impunidad de la muerte de otro por parte de un médico o de cualquier otra persona bajo su dirección, dadas ciertas condiciones ${ }^{58}$.

También con posterioridad a la entrada en vigor del CP de 1995 se han seguido efectuando propuestas que resulta imposible detallar en este espacio. Entre las que más concreción han alcanzado se encuentra la de una conocida autora ${ }^{59}$ que propone, entre otras modificaciones ${ }^{60}$, el mantenimiento de la vigencia del art. 143.4 CP, introduciendo la referencia a los documentos de voluntades anticipadas y la creación de un nuevo apartado en el que se prevea expresamente la permisión de la eutanasia en sus tres modalidades, activa, activa indirecta y pasiva, incluso sin concurrir la petición seria y expresa ni el documento de voluntades anticipadas, siempre que se lleve a efecto tras haberse cumplido con un procedimiento en el que se valore cuál es el mejor interés del paciente. En este procedimiento propone que intervengan dos facultativos, uno, el responsable del paciente, y otro que no lo haya tratado, así como los familiares y el Comité de ética del hospital, pudiendo requerirse incluso una resolución judicial para casos dudosos. Opta por incluir la eutanasia pasiva porque, cuando el paciente no puede consentir, incluso esa modalidad debe ser objeto de una decisión consensuada.

57 Integrado por un importante número de profesores, jueces y fiscales, V. Una alternativa al tratamiento jurídico de la disponibilidad de la propia vida, Grupo de Estudios de Política Criminal, 1993.

58 Que medie la solicitud expresa, libre y seria de una persona mayor de 18 años que tenga capacidad natural de juicio, siempre que esta padezca graves sufrimientos no evitables ni notoriamente atenuables de otro modo y que se deriven de una afección incurable que le conducirá próximamente a la muerte 0 que, siendo permanente le incapacita de manera generalizada para valerse por sí misma.

59 Mirentxu Corcor Bidasolo, Autonomía personal, cit., pp. 320 ss.

60 La de la Ley 41/2002, reguladora de la autonomía del paciente, en lo relativo a los documentos de voluntades anticipadas y al consentimiento con representación. Considera que se debería concretar lo prescrito en el art. 9.5, en relación con la necesidad de atender siempre al mejor interés del paciente y al respeto de su dignidad personal, en los casos en que el consentimiento sea por representación. Concreción que pasaría por determinar quién y cómo se valora qué tratamiento o no-tratamiento es el mejor y más respetuoso con la dignidad. Y, además, desarrollar una legislación que establezca un procedimiento para determinar con la máxima seguridad jurídica si concurren los requisitos en cada caso concreto para realizar la práctica de la eutanasia. 
De esta forma considera que, además, se disminuye la carga emocional que para el responsable del tratamiento supone una decisión de esta naturaleza.

\subsubsection{Consideraciones finales}

Entendemos que la eutanasia es un problema pendiente, y pendiente de regulación. Las peticiones de ayuda a morir en situaciones límite constituyen un drama que debería ser abordado, pero con importantes cautelas.

Porque no parece que deban trivializarse las consideraciones con las que se pretende ponerle límites. Así, los riesgos de abusos como consecuencia de no articular adecuados controles que limiten la práctica real a los supuestos que se prevean, ya porque se consiga someter al enfermo a variadas clases de presión incluso muy sutiles de familiares, etc., o porque la permisión pueda llevar a la generalización de prácticas eutanásicas como alternativa más económica que la de las terapias paliativas (supuestos fácticos de lo que se ha dado en llamar los argumentos - político-criminalesde la pendiente resbaladiza ${ }^{61}$ ) deben ser tenidos muy en cuenta si se aborda esta tarea. Se sostiene, además, como obstáculo para la posible regulación, si es necesario dar tal paso en el que el médico, que hasta ahora únicamente estaba obligado a curar y a mitigar el dolor, se convierta en ejecutor de muertes cuasi oficiales y con ello cambiar drásticamente su imagen profesional, cuando, de acuerdo con la información que suministran los médicos, los pacientes raras veces solicitan su muerte y que tales deseos de morir pueden reducirse con una eficaz terapia para el dolor que haga desaparecer los motivos para la petición de una muerte anticipada ${ }^{62}$.

No cabe duda de que cualquier regulación que se intente en la materia debería estar avalada por un exhaustivo conocimiento del sistema sanitario de cada país y desarrollarse en relación con él, y que resulta prioritario impulsar y extender (como derecho de toda la población) el acceso a terapias paliativas que permitan reducir el sufrimiento, circunstancia que muy probablemente produciría como consecuencia

61 V. extensamente, Carmen Tomás-Valente Lanuza, La disponibilidad de la propia vida, 1999, pp. 124-151; Fernando Rey Martínez, Eutanasia y derechos fundamentales, cit., pp. 175 ss.

62 Claus Roxin, "Tratamiento jurídico-penal de la eutanasia", traducción de Miguel Olmedo Cardenete, en Eutanasia y suicidio. Cuestiones dogmáticas y de política criminal, Granada, Comares, 2001, pp. 3-38., atribuye esta advertencia a los adversarios de la eutanasia activa, pero sostiene que "no puede discutirse seriamente que la combinación entre una muerte asistida en la que se prestan mayores atenciones humanas y una terapia del dolor más eficaz no constituye, frente al homicidio a petición, un mejor camino para el tratamiento de quien está sufriendo en el umbral de la muerte. Tampoco resulta descabellado el temor a que una aceptación (limitada) del homicidio a petición pudiera constituir el potencial desmantelamiento tanto de una terapia paliativa, que de todos modos está atrasada en Alemania, como de importantes exigencias humanas de una muerte asistida más intensiva, porque está a disposición un camino aparentemente más sencillo. Eso no sería una solución humanitaria", asumiendo así uno de los supuestos que integran los argumentos de la llamada pendiente resbaladiza. 
una reducción en las peticiones de ayuda a morir launque nos parece absolutamente incorrecto plantear la cuestión cuidados paliativos/eutanasia en relación de alternatividad ${ }^{63}$ ); pero también sabemos que los conocimientos médicos conseguidos hasta el momento no permiten, en algunos casos, paliar enormes sufrimientos, y rechazar toda posibilidad de auxilio a estas personas (cuando lo pidan, en muy limitados supuestos, con estrictos procedimientos de control y en el ámbito sanitario) por los riesgos que el auxilio pueda traer aparejado es adoptar la decisión de dejarlas abandonadas.

Resulta significativo que en España, ni estando vigente la anterior legislación ni con el surgimiento del CP de 1995 (que regula los supuestos eutanásicos analizados), haya ninguna sentencia condenatoria en casos de cooperación o ejecución de la muerte de otro en un contexto eutanásico. Al respecto, se ha sostenido que aunque parezca que no hay un modelo público de respuesta al problema de la eutanasia, sí lo hay, y es el que remite la cuestión de las decisiones sobre el final de la vida a la penumbra de acto médico concreto, reconociendo que esta situación genera inseguridad y desigualdad ${ }^{64}$. Si bien podría considerarse que esta escasa o inexistente voluntad político-criminal de perseguir las conductas que en este ámbito pudieran producirse ${ }^{65}$ puede resultar menos mala que los riesgos de una regulación, tal pensamiento no convence, porque de existir estas prácticas estarían produciendo como consecuencia tratos desiguales injustificables y situarían al médico que las realizase en una situación de inseguridad poco tolerable, situación de inseguridad que se ha producido, no ya por la posible realización de una práctica delictiva (como lo es la eutanasia activa directa en nuestro país), sino por extender la sedación terminal a los enfermos que la requirieran (supuestos que, en todo caso, se enmarcarían la en denominada eutanasia activa indirecta, conducta impune de acuerdo a nuestra legislación) ${ }^{66}$.

63 En igual sentido, Fernando Rey Martínez, Eutanasia y derechos fundamentales, cit., p. 192.

64 Fernando Rey Martínez, Eutanasia y derechos fundamentales, cit., pp. 190 s., aunque considera que el rendimiento global del sistema parece razonable.

65 No existe ningún dato fiable que dé cuenta del alcance de la posible cifra negra en el ámbito de la eutanasia.

66 En el llamado "Caso Leganés" en el año 2005 se denunció como sospechosos de homicidio a un grupo de médicos del Hospital Severo Ochoa, de Leganés, Madrid. Tras tres años de proceso, la Audiencia Provincial de Madrid (Auto 47/2008, de 21 de enero) confirmó (en una resolución definitiva) el sobreseimiento provisional dictado por el Juzgado de Instrucción $\mathrm{n}^{0} 7$ de Leganés, pero debiendo tener por suprimida de su fundamentación jurídica toda mención realizada en el auto recurrido respecto a la mala praxis médica por parte de los querellados. 


\section{Bibliografía}

Álvarez García, F. Javier, Álvarez García, F. Javier, (Dir) Derecho Penal Español, Parte Especial, I, Valencia, Tirant lo Blanch, 2010.

Bajo Fernández, Miguel, PE, I, 1991.

Barber Burusco, Soledad, Los actos preparatorios del delito, Granada, Comares, 2004. Barouín Sanz, Jesús, "La eutanasia como forma de intervención en la muerte de otro" en Eutanasia y suicidio. Cuestiones dogmáticas y de política criminal, Granada, Comares, 2001.

Carbonell Mateu, Juan Carlos, "Libre desarrollo de la personalidad y delitos contra la vida. Dos cuestiones: suicidio y aborto" en Cuadernos de Política Criminal 45, 1991.en el CP español. Propuestas de reformas legislativas" en Mendoza Buergo, Blanca (ed.), Autonomía personal y decisiones médicas. Cuestiones éticas y jurídicas, Madrid, Civitas, 2010.

Carbonell Mateu, Juan Carlos, Vives Antón, Tomás y otros, Derecho Penal. Parte Especial, Valencia, Tirant lo Blanch, 2008.

Corcoy Bidasolo, Mirentxu / Gallego Soler, José Ignacio, "Política criminal en el ámbito de la disponibilidad de la vida humana" en Mir Puig, Santiago/Corcoy Bidasolo, Mirentxu (dirs.) Política criminal y reforma penal, Montevideo-Buenos Aires, B de F, 2007.

Corcoy Bidasolo, Mirentxu, "La regulación legal de la eutanasia en el CP español. Propuestas de reformas legislativas" en Mendoza Buergo, Blanca (ed.), Autonomía personal y decisiones médicas. Cuestiones éticas y jurídicas, Madrid, Civitas, 2010.

Del Rosal Blasco, Bernardo, "El tratamiento jurídico-penal y doctrinal de la eutanasia en España", en Díez Ripollés, José Luis/Muñoz Sánchez, Juan (coords.), El tratamiento jurídico de la eutanasia. Una perspectiva comparada, Valencia, Tirant lo Blanch, 1996.

Del Rosal Blasco, Bernardo, "La participación y el auxilio ejecutivo en el suicidio: un intento de reinterpretación constitucional del artículo 409 del Código Penal", en Anuario de Derecho Penal y Ciencias Penales, 1987.

Díaz Aranda, Enrioue, Dogmática del suicidio y homicidio consentido, Madrid, Centro de Estudios Judiciales, 1995.

Díazy García Conlledo, Miguel, "iEs necesaria la cooperación necesaria?" Libro-Homenaje al Prof. Dr. D. José Cerezo Mir, Comares, Granada, 2002, pp. 645-669, publicado en Argentina en: Revista de Derecho Penal 2005-2. Autoría y participación - II (Buenos Aires).

Díaz y García Conlledo, Miguel, "Autoría”, en EPB, 2002.

Díaz y García Conlledo, Miguel, “Conspiración, proposición y provocación”, en EPB, 2002. Díaz y García Conlledo, Miguel, "Cooperación necesaria y complicidad”, en EPB, 2002. 
Díaz y García Conlledo, Miguel, "Homicidio consentido, participación en el suicidio y eutanasia" en Luzón Peña, Diego-Manuel (dir.), Enciclopedia Penal Básica, Granada, Comares, 2002.

Díez Ripoltés, José Luis, "Eutanasia y Derecho" en Díez Ripollés, José Luis/ Muñoz Sánchez, Juan (coords.) El tratamiento jurídico de la eutanasia. Una perspectiva comparada, Valencia, Tirant lo Blanch, 1996.

Díez Ripollés, José Luis, Díez Ripollés, José Luis/Gracia Martín, Luis (coords.), Comentarios al Código Penal, I, Valencia, Tirant lo Blanch, 1997.

Gimbernat Ordeig, Enrioue, Prólogo a la segunda edición del Código Penal, 17aa, Madrid, Tecnos, 2011.

Gómez Rivero, María del Carmen, "La intervención omisiva en el suicidio de un tercero" en Actualidad Penal 45, 1998.

González Rus, Juan José, PE, 2005.

Jorge Barreiro, Agustín, Rodríguez Mourullo, Gonzalo (dir.) Comentarios al Código Penal, Madrid, Civitas, 1997.

Juanatey Dorado, Carmen, Boix Reig, Javier (dir.), Derecho Penal. Parte Especial, I, lustel, 2010.

Luzón Peña, Diego-Manuel, “El consentimiento en Derecho penal: causa de atipicidad, de justificación o de exclusión sólo de la tipicidad" en Homenaje al Prof. Dr. Rodrigo Suárez Montes (en prensa).

Luzón Peña, Diego-Manuel, "La participación por omisión en la jurisprudencia reciente del TS" en LUZÓN PEÑA, Diego-Manuel: Estudios Penales, Barcelona, PPU, 1991.

Mendes de Carvalho, Gisele, Suicidio, eutanasia y Derecho Penal, Granada, Comares, 2009.

Mir Puig, Santiago, Derecho Penal. Parte General, ga ed. a cargo de Víctor Gómez Martín, Barcelona, Reppertor, 2011.

Muñagorri Laguía, Ignacio, Eutanasia y Derecho penal, Madrid, Ministerio de Justicia e Interior, 1994.

Muñoz Conde, Francisco, Derecho Penal. Parte Especial, 18. ${ }^{a}$, Valencia, Tirant lo Blanch, 2010.

Núñez Paz, Miguel Ángel, Homicidio consentido, eutanasia y derecho a morir con dignidad, Madrid, Tecnos, 1999.

Núñez Paz, Miguel Ángel, La buena muerte. El derecho a morir con dignidad, Madrid, Tecnos, 2006.

Olmedo Cardente, Miguel, "Eutanasia, suicidio y Derecho penal en España. Responsabilidad penal por la intervención en el suicidio ajeno y en el homicidio consentido" en Eutanasia y suicidio. Cuestiones dogmáticas y de política criminal, Granada, Comares, 2001. 
Rey Martínez, Fernando, Eutanasia y derechos fundamentales, Madrid, Centro de Estudios Constitucionales, 2008Francisco Bueno Arús, "Límites del consentimiento en la disposición del propio cuerpo desde la perspectiva del Derecho penal" en Poder Judicial n. 15., 1985.

Romeo Casabona, Carlos, Derecho y bioética ante los límites de la vida humana, Madrid, 1994.

Romeo Casabona, Carlos, Los delitos contra la vida y la integridad personal y los relativos a la manipulación genética, Granada, Comares, 2004.

Roxin, Claus, "Tratamiento jurídico-penal de la eutanasia", traducción de Miguel Olmedo Cardenete, en Eutanasia y suicidio. Cuestiones dogmáticas y de política criminal, Granada, Comares, 2001.

Serrano Gómez, Alfonso / Serrano Maílo, Alfonso, Derecho Penal. Parte Especial, 16 ed., Madrid, Dykinson, 2011.

Silva Sánchez, Jesús María, "Causación de la propia muerte y responsabilidad penal de terceros" en Anuario de Derecho Penal y Ciencias Penales, 1987.

Toledano Toledano, Jesús, Límites penales a la disponibilidad de la propia vida, Barcelona, Atelier, 1999.

Tomás-Valente lanuza, Carmen, Disponibilidad de la propia vida en el Derecho Penal, Madrid, Boletín Oficial del Estado, 1999.

Tomás-Valiente Lanuza, Carmen, La cooperación al suicidio y la eutanasia en el nuevo CP (art.143), Valencia, Tirant lo Blanch, 2000.

Torío López, Ángel, "La noción jurídica de suicidio" en Estudios de Derecho Público y Privado. Homenaje a D. Ignacio Serrano y Serrano, I, Valladolid, 1965. 